\title{
Antibiotic Combination Therapy: A Strategy to Overcome Bacterial Resistance to Aminoglycoside Antibiotics
}

\author{
Nuoyan Wang, Jing Luo, Fei Deng, Yasi Huang and Hong Zhou* \\ Key Laboratory of Basic Pharmacology, Ministry of Education and Joint Laboratory of International Cooperation, Ministry of \\ Education of Characteristic Ethnic Medicine, School of Pharmacy, Zunyi Medical University, Zunyi, China
}

\section{OPEN ACCESS}

Edited by:

Younes Smani,

Andalusian Center for Development

Biology (CSIC), Spain

Reviewed by:

Xiancai Rao,

Army Medical University, China Michal Letek,

Universidad de León, Spain

*Correspondence: Hong Zhou

zhouh64@163.com

Specialty section:

This article was submitted to Pharmacology of Infectious Diseases, a section of the journal

Frontiers in Pharmacology

Received: 20 December 2021 Accepted: 08 February 2022

Published: 23 February 2022

Citation:

Wang N, Luo J, Deng F, Huang Y and Zhou H (2022) Antibiotic Combination

Therapy: A Strategy to Overcome

Bacterial Resistance to

Aminoglycoside Antibiotics.

Front. Pharmacol. 13:839808.

doi: 10.3389/fphar.2022.839808
After the first aminoglycoside antibiotic streptomycin being applied in clinical practice in the mid-1940s, aminoglycoside antibiotics (AGAs) are widely used to treat clinical bacterial infections and bacterial resistance to AGAs is increasing. The bacterial resistance to AGAs is owed to aminoglycoside modifying enzyme modification, active efflux pump gene overexpression and 16S rRNA ribosomal subunit methylation, leading to modification of AGAs' structures and decreased concentration of drugs within bacteria. As AGAs's side effects and bacterial resistance, the development of AGAs is time-consuming and difficult. Because bacterial resistance may occur in a short time after application in clinical practice, it was found that the antibacterial effect of the combination was not only better than that of AGAs alone but also reduce the dosage of antibiotics, thereby reducing the occurrence of side effects. This article reviews the clinical use of AGAs, the antibacterial mechanisms, the molecular mechanisms of bacterial resistance, and especially focuses a recent development of the combination of AGAs with other drugs to exert a synergistic antibacterial effect to provide a new strategy to overcome bacterial resistance to AGAs.

Keywords: aminoglycoside antibiotics, antibacterial mechanisms, bacterial resistance mechanisms, synergy, side effects

\section{INTRODUCTION}

Streptomycin was the first discovered aminoglycoside antibiotic (AGA) to be used for tuberculosis treatment in the mid-1940s (Schatz et al., 2005). Thereafter, a series of aminoglycoside antibiotics (AGAs) were discovered, including neomycin (1949), gentamicin (1963), tobramycin (1967), sisomycin (1970), amikacin (1972), and plazomicin (2006) (Figure 1), and all were found to have good antibacterial activities not only for gram-negative bacteria but also for some gram-positive bacteria (Becker and Cooper, 2013; Clark and Burgess, 2020). AGAs are composed of amino sugars and aminocyclic alcohols. 2-deoxystreptamine (2-DOS) is the central unit, which is connected with 2-3 sugar units through glycosidic bonds (Figure 2) (Stead, 2000). According to the structural differences, AGAs are divided into two categories: one is with a 2-deoxystreptamine (2-DOS) core site and another is without a 2-DOS core site (e.g., streptomycin). In turn, according to the substituent linkage position the core site is divided into 4,5-disubstituted 2-DOS and 4,6disubstituted 2-DOS. The chemical structure of 2-deoxystreptamine is as follows (Figure 2). The structural feature of 4,5 disubstituted 2-DOS AGAs is that the hydroxyl groups at the C-4 and C-5 positions of the 2-DOS ring are substituted and connected to the sugar ring by a glycosidic bond; in 


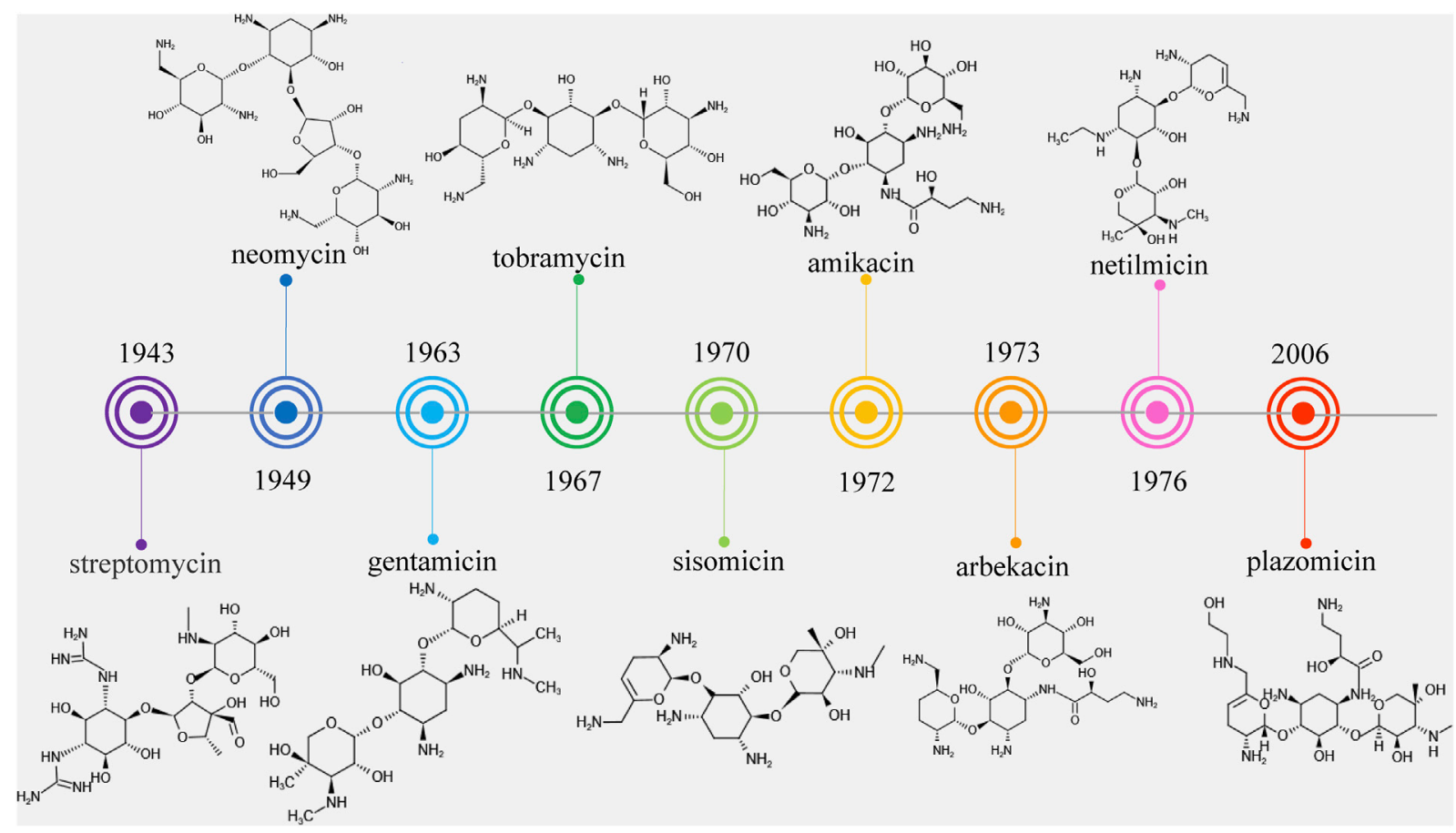

FIGURE 1 | Timeline of aminoglycoside antibiotics development

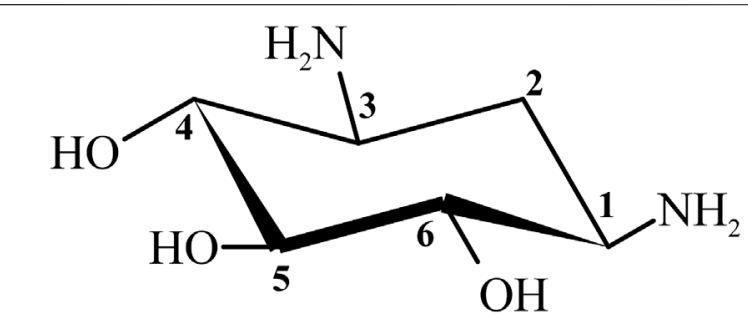

FIGURE 2 | Chemical structure of 2-deoxystreptamine (2-DOS).

4,6-disubstituted 2-DOS AGAs, the hydroxyl groups at the C-4 and C-6 positions of the 2-DOS ring are substituted and connected to the sugar ring by a glycosidic bond. These sugar units generally have multiple hydroxyl and amino groups, so they have the advantages of good water solubility, good functionality and wide antibacterial spectrum (Johnston et al., 2002).

However, because of the widespread use of these antibiotics, side effects such as nephrotoxicity, ototoxicity and neuromuscular blockade have been found, and bacterial resistance has become more and more frequent. Therefore, the third-generation AGAs such as amikacin (1972), arbekacin (1973), and netilmicin (1976) developed (Kudo and Eguchi, 2016).

AGAs development can be divided into three stages, also known as three generations, based on chemical structure, antibacterial spectrum and resistance to bacterial modification enzymes (Lin, 2001). The first generation of AGAs is represented by kanamycin, which is characterized by the binding of fully hydroxylated amino sugars and cyclic alcohols and no antimicrobial activity against pseudomonas aeruginosa ( $P$. aeruginosa). The second generation is represented by gentamicin, which contains deoxyamino sugars in the structure and has antibacterial activity against $P$. aeruginosa. The third generation is represented by amikacin, a semisynthetic derivative of amino cyclic alcohol substituted at the nitrogen position. The third generation of AGAs is characterized by preserving their antibacterial activity while reducing their side effects after modification of their mother nucleus, and has the potential for clinical application due to its characteristics of low drug resistance potential and high plasma concentration (Ristuccia and Cunha, 1982).

However, it was subsequently discovered that these AGAs had limited antibacterial activities against aminoglycosidemodifying enzyme (AME)-producing bacteria. With the development and use of broad-spectrum antibiotics with fewer side effects such as $\beta$-lactam antibiotics and fluoroquinolones, the market shares of AGAs decreased and the search for new AGAs has been scaled back. Plazomicin (formerly ACHN-490) is a new type of parenteral drug targeting multidrug-resistant Enterobacteriaceae, including AME-producing bacteria, extended-spectrum beta-lactamase (ESBL) and carbapenemase of microorganisms (Haedersdal et al., 2016; Castanheira et al., 2018), which was approved by the Food and Drug Administration (FAD) in June 2018 for the treatment of complicated urinary tract infections (cUTI) and pyelonephritis caused by microorganisms (Saravolatz 
TABLE 1 | Resistance rates of common gram-positive cocci to gentamicin.

\begin{tabular}{ll} 
Genus names & \multicolumn{1}{c}{ Bacteria names } \\
Staphylococcus spp. & Staphylococcus aureus \\
& Methicillin resistant bacteria of staphylococcus epidermidis \\
& Other staphylococcus bacteria (except pseudointermediate staphylococcus and staphylococcus schleiferi) \\
& Methicillin-sensitive strains of S. aureus \\
& Methicillin-sensitive strains of S. epidermidis \\
& Other staphylococcus bacteria (except pseudointermediate staphylococcus and staphylococcus schleiferi) \\
Enterococcus spp. & E. faecalis \\
& E. faecium
\end{tabular}

TABLE 2 | Resistance rates of common gram-negative bacilli to gentamicin and amikacin.

\begin{tabular}{|c|c|c|c|}
\hline Genus names & Bacteria names & $\begin{array}{c}\text { Resistance rate of } \\
\text { gentamicin (\%) }\end{array}$ & $\begin{array}{c}\text { Resistance rate of } \\
\text { amikacin (\%) }\end{array}$ \\
\hline \multirow[t]{2}{*}{ Enterobacterale spp. } & Escherichia coli & 37.4 & 2.7 \\
\hline & Klebsiella & 28.9 & 15.7 \\
\hline \multirow[t]{2}{*}{ Non-fermentative gram-negative bacilli } & Pseudomonas aeruginosa & 8.3 & 4.5 \\
\hline & Acinetobacter & 65.3 & 50.7 \\
\hline
\end{tabular}

and Stein, 2020). It became the first FDA-approved AGAs after amikacin was approved in 1981, marking the return of AGAs to the market (Figure 1).

In 2013, the Center for Disease Control (CDC) released the first threat report on antibiotic-resistant (AR) bacteria in the United States. The CDC's US Antibiotic Resistance Threat 2019 (AR Threat Report 2019) includes up-to-date estimates of the number of deaths and bacterial infections nationwide, reemphasizing the ongoing threat of antibiotic resistance in the United States. More than 2.8 million infections resulting from antibiotic resistance occur in the United States each year, and more than 35,000 people die from infections. New CDC data show that despite the growing threat of antibiotic resistance in the United States, for example, erythromycin-resistant invasive group A streptococcus increased by $351 \%$, drug-resistant neisseria gonorrhoeae increased by $124 \%$, and ESBL-producing enterobacteriaceae increased by $50 \%$, the number of deaths has decreased since the 2013 report, including an $18 \%$ reduction in overall deaths and a $28 \%$ reduction in hospital deaths resulting from antibiotic resistance (Antibiotic resistance threats in the United States, 2019, 2019).

According to the CHINET surveillance of bacterial resistance, results of 2020 published in the Chinese Journal of Infection and Chemotherapy in July 2021 (Hu et al., 2021). The susceptibility of clinical isolates from 52 hospitals in major regions of China to antibacterial drugs was tested, and the judgment criteria were based on the 2020 Clinical and Laboratory Standards Institute (CLSI) Drug Sensitivity Judgment Standard (Humphries et al., 2021). In 2020, the proportions of clinical isolates of gramnegative and gram-positive bacteria collected from the above 52 hospitals were 71.9 and $28.1 \%$, respectively.

The resistance rate of gentamicin, a representative drug of AGAs, was calculated on gram-positive coccis and found that, methicillin-resistant staphylococcus aureus (MRSA), enterococcus faecalis (E. faecalis) and enterococcus (E. faecium) are severely resistant to gentamicin. Most of the methicillin-sensitive staphylococci were sensitive to gentamicin (Table 1) (Hu et al., 2021). After statistics of the bacterial resistance rates to gentamicin and amikacin in enterobacterales strains of gramnegative bacilli with high clinical isolation rate, it was found that the resistance of Klebsiella to gentamicin and amikacin and escherichia coli (E. coli) to gentamicin are relatively serious, while $E$. coli is relatively sensitive to amikacin. Among non-fermentative gram-negative bacilli, $P$. aeruginosa was mostly sensitive to gentamicin and amikacin, while acinetobacter was severely resistant to the two AGAs (Hu et al., 2021) (Table 2)

\section{ANTIBACTERIAL MECHANISM OF AMINOGLYCOSIDE ANTIBIOTICS}

The binding of $30 \mathrm{~S}$ ribosomal subunit and tRNA is one of the key step in protein synthesis. Researches have shown that there are three sites where tRNA and $30 \mathrm{~S}$ subunit bind, comprising Aminoacyl (A), Peptide (P), and Exit (E) sites (Tsai et al., 2013). The potent bactericidal activity of AGAs mainly depends on their specific binding to the A site of the bacterial ribosomal $30 \mathrm{~S}$ subunit $16 \mathrm{~S}$ rRNA, interfering with the bacterial intracellular translation process to inhibit bacterial protein synthesis (Degtyareva et al., 2017). However, unlike other commonly used protein synthesis inhibitors, AGAs are bactericidal antibiotics, while common inhibitors of protein synthesis such as chloramphenicol, clindamycin, tetracycline and macrolides are bacteriostatic antibiotics (Serio et al., 2018). Recent studies have discovered that aminoglycoside bactericidal antibiotics act on both gram-negative bacteria and gram- 


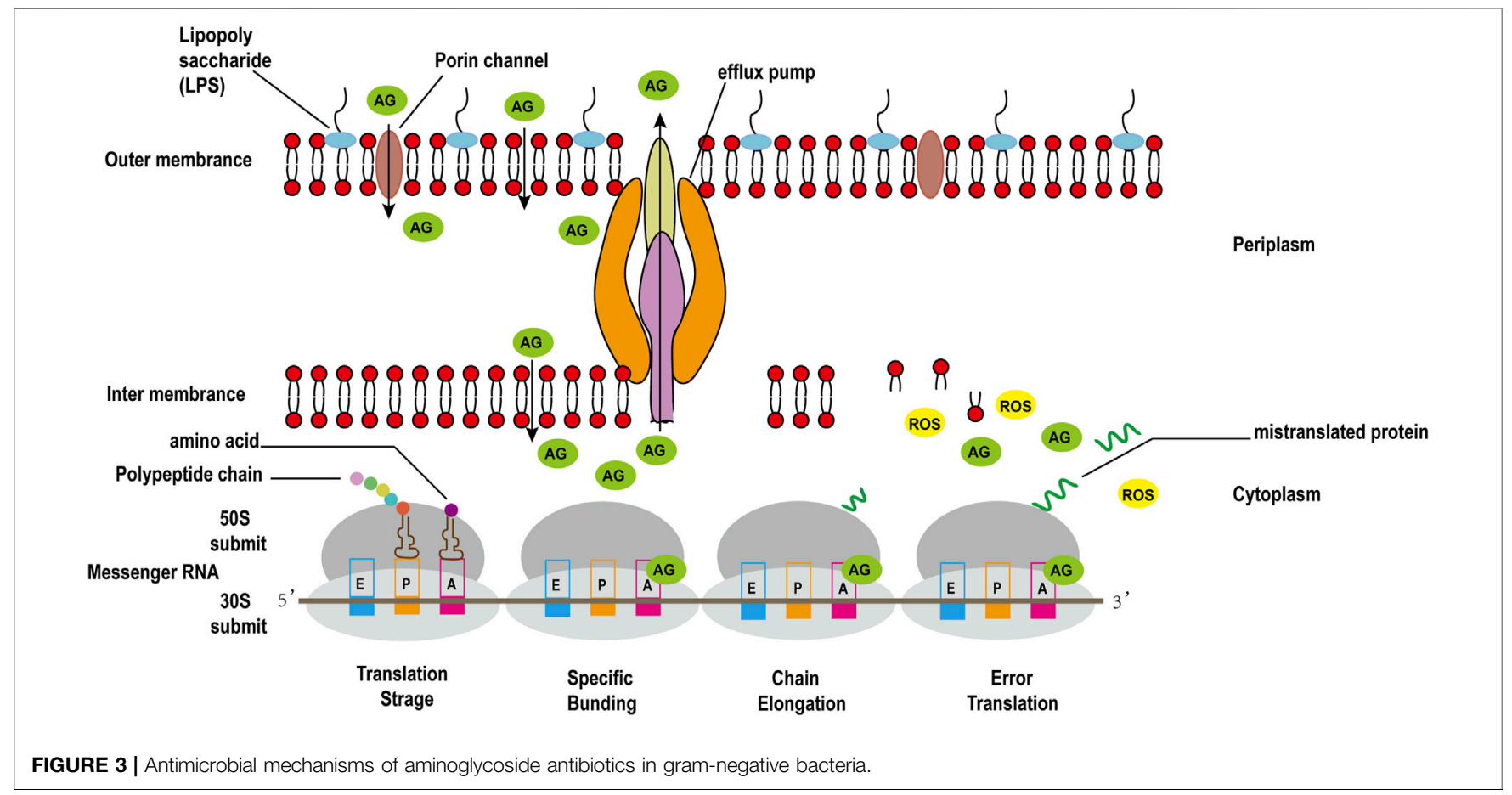

positive bacteria to produce hydroxyl free radicals that are harmful to the bacteria, ultimately leading to their death (Figure 3), while bacteriostatic antibiotics do not promote the production of hydroxyl free radicals (Kohanski et al., 2007).

\section{BACTERIAL RESISTANCE MECHANISM TO AMINOGLYCOSIDE ANTIBIOTICS}

\subsection{Enzymatic Modification of Aminoglycoside Antibiotics}

Among various bacterial resistance mechanisms to AGAs, AMEs is the most common mechanism (Wachino et al., 2020). AMEs are divided into three aminoglycoside modifying enzyme families: phosphotransferases (APHs), acetyltransferases (AACs), and adenyl transferases (ANTs) (Sparo et al., 2018). These AMEs use cofactors, acetyl-coenzyme A or ATP to modify $\mathrm{NH}_{3}$ or $\mathrm{OH}$ groups of AGAs, thereby inactivating them. The genes encoding AMEs are usually carried in plasmids, which promotes the bacterial-bacterial spread of aminoglycoside resistance (Bassenden et al., 2016). Clinically isolated aminoglycoside resistant strains often harbor multiple AME genes, and it is reported that the AME gene is encoded on the same plasmid as the 16S-ribosomal RNA methyltransferases (RMTase) gene (Garneau-Tsodikova and Labby, 2016; López Díaz et al., 2017). The three types of AMEs comprise many subtypes, each with a certain specificity for resistance to AGAs (Garneau-Tsodikova and Labby, 2016).

\subsubsection{Acetyltransferases}

Acetyltransferases (AACs) acetylate the amino group $\left(-\mathrm{NH}_{2}\right)$ on aminoglycoside molecules, and are members of the $\mathrm{N}$-acetyltransferase (GNAT) superfamily, which are thought to be related to general control non-depressible 5 (GCN5) (Ramirez et al., 2013). The enzyme is divided into four subtypes according to the location of catalytic acetylation: AAC (1), $\left(2^{\prime}\right),(3)$, and $\left(6^{\prime}\right)$ (Ramirez and Tolmasky, 2010).

AAC $\left(6^{\prime}\right)$ enzymes are widespread in gram-negative as well as gram-positive bacteria and are by far the most common, and their genes have been found in plasmids and chromosomes, and are part of mobile genetic elements (Tolmasky, 2000; Centrón and Roy, 2002; Soler Bistué et al., 2008). A group of gram-negative and gram-positive bacteria caused by nosocomial infections called as ESKAPE (E. faecium, staphylococcus aureus (S. aureus), klebsiella pneumoniae (K. pneumoniae), acinetobacter baumannii, $P$. aeruginosa, and enterobacter) are highly resistant to antibiotics including AGAs (Rice, 2008). The most common gram-negative member of the AME genes they carry is aac (6 $\left.6^{\prime}\right)$ -Ib(Ramirez and Tolmasky, 2010; Shaul et al., 2011; Herzog et al., 2012). N-acetyltransferase AAC (3)-I was established as a selectable marker for gentamicin-based oomycete transformation, and it was found that $\mathrm{N}$-acetyltransferase AAC (3)-I was responsible for gentamicin resistance in phytophthora palmivora and phytophthora infestans (Evangelisti et al., 2019).

\subsubsection{Phosphotransferases}

Phosphotransferase (APH) enzymes transfer a phosphate group from ATP to the hydroxyl group (-OH) on the aminoglycoside 
molecule, and comprise seven subtypes: APH $\left(2^{\prime \prime}\right),\left(3^{\prime}\right),\left(3^{\prime \prime}\right),(4)$, (6), ( $\left.7^{\prime \prime}\right)$, and (9). The aph (6) -Id gene was first discovered in plasmid RSF1010, an 8,684 bp wide host range multicopy plasmid RSF1010 that can replicate in most gram-negative and grampositive actinomycetes (Meyer, 2009), and this plasmid is also the first source of another APH- $a p h$ ( $\left.3^{\prime \prime}\right)-I b$, adjacent to $a p h$ (6) -Id (Daly et al., 2005; Gordon et al., 2008). Due to the spread of this DNA fragment, $a p h$ (6) - Id and aph (3") - Ib genes were found in both gram-positive and gram-negative bacteria (Ramirez and Tolmasky, 2010). APH $\left(3^{\prime}\right)$ enzymes induce resistance to amikacin, kanamycin and neomycin of AGAs (Aggen et al., 2010; Ramirez and Tolmasky, 2010; Miró et al., 2013).

\subsubsection{Adenyl Transferases}

Adenyl transferase (ANT) enzymes transfer the adenosine monophosphate (AMP) group in ATP to the hydroxyl group $(-\mathrm{OH})$ of aminoglycoside molecules. There are five classes of this of enzyme: ANT (2"), $\left(3^{\prime \prime}\right),\left(4^{\prime}\right),(6)$, and (9). ANT (2")-Ia is an enzyme normally encoded by plasmids and transposons, widely distributed as gene cassettes in class 1 and class 2 integrons (Vakulenko and Mobashery, 2003; Ramírez et al., 2005). This enzyme mediates resistance to gentamicin, tobramycin, dibecacin, sisomicin and kanamycin of Enterobacteriaceae and non-fermentative gram-negative bacilli (Ramirez and Tolmasky, 2010). Compared with AACs and APHs, ANTs are found less frequently in enterobacteriaceae and $P$. aeruginosa, but still act as an important role of bacterial resistance to AGAs (Almaghrabi et al., 2014; Holbrook and Garneau-Tsodikova, 2018).

\subsection{Decreased Drug Accumulation}

\subsubsection{Increased Efflux Pumps}

The active efflux of antibiotics from bacteria plays an important role in various antibiotic resistance mechanisms. It can also interact with other drug resistance mechanisms such as membrane permeability changes, enzymatic modification of antibiotics, and changes to the target of antibiotic action, thereby significantly increasing antibiotic resistance levels (Li et al., 2015). In P. aeruginosa, the MexXY-OprM system confers low-level intrinsic resistance to AGAs, and mutations to the mexZ repressor, which are expressed from the mexXY operon, induce widespread AGAs resistance in clinical isolates (Poole, 2011). In E. coli and other members of Enterobacteriaceae spp., the AcrAD-TolC system cause the efflux of AGAs and other antibiotics (Li et al., 2015; Garneau-Tsodikova and Labby, 2016). Perhaps because of the significance of AMEs in the mechanism of AGAs resistance, the clinical resistance of Enterobacteriaceae spp. to AGAs through active efflux pumps is rarely reported.

\subsubsection{Reduced Bacterial Outer Membrane Permeability}

\subsubsection{Mutations of Genes Encoding Porins}

To take up nutrients, bacteria have evolved many absorption mechanisms. One of which is the formation of water-filled pores extending through the membrane to promote the absorption of hydrophilic compounds. The proteins that form these channels are called porins. Drug resistance caused by porins mutations include: decreased expression, no expression, and structural mutations. Antibiotic resistance caused by changes in porin expression and their mutations might be a limited resistance mechanism because they can also lead to reduced nutrient intake by bacteria (Garneau-Tsodikova and Labby, 2016). AGAs have a hydrophilic structure and a positive charge; therefore, they are believed to penetrate bacterial cell walls through porin channels instead of directly diffusing through the phospholipid bilayer (Nikaido and Pagès, 2012). Beta-lactams, fluoroquinolones, tetracycline antibiotics, and other antibiotics also enter the bacterial membrane through porins, and the loss of porins on the membrane will lead to resistance to these antibiotics. It was found that mutants of $E$. coli lacking porin $\mathrm{OmpF}$ are resistant to AGAs (Bafna et al., 2020). However, the survival rate of the OmpF mutant of E. coli is lower than that of the wild-type; thus it might not be widespread in clinically isolated strains (Zhao et al., 2014).

\subsubsection{Membrane Protease and Other Functional Proteins}

Membrane protease, as a member of the protein synthesis system, is used to identify and degrade misfolded and translated proteins. As AGAs accumulate in bacteria, they will produce mistranslated proteins. Membrane proteases recognize and remove them, thereby producing resistance to AGAs. Studies have shown that proteolysis plays a central role in the mechanism of the intrinsic resistance to AGAs of $P$. aeruginosa, in which the membrane protease FtsH is particularly important (Hinz et al., 2011). Deletions of genes related to lipid biosynthesis or metabolism (lptA, faoA), phosphate uptake (pstB), twocomponent regulators (amgRS, PA2797-PA2798), and a gene with unknown function (PA0392) also increased the sensitivity to AGAs, such as gentamicin, confirming their contribution to intrinsic resistance (Krahn et al., 2012).

\subsubsection{Biofilm Formation}

The ability of bacteria to form biofilm enhances their ability to infect the host, which is usually associated with chronic infections by invasive bacteria (Yarlagadda and Wright, 2019). A biofilm is a collection of microorganisms attached to the surface of living organisms or non-living organisms, and is embedded in the matrix of extracellular polymeric substances (EPSs), including proteins, extracellular polysaccharides, and extracellular DNA (eDNA) (Das et al., 2013). The eDNA produced during cell lysis is an important part of the biofilm. The eDNA in P. aeruginosa can acidify the environment and induce the function of the PhoPQ and PmrAB two-component regulatory system to regulate gene expression, thereby enhancing aminoglycoside resistance (Wilton et al., 2016). The complex structure of a biofilm can protect the bacteria from the host's immune system and antibacterial drugs (Lebeaux et al., 2014). The general mechanisms by which biofilm-mediated resistance protects bacteria from antibiotic attack include preventing antibiotic penetration, altering the microenvironment to induce slow growth of biofilm cells, induction of adaptive stress responses, and sustained cell differentiation (Stewart, 2002). Biofilmmediated drug resistance is an adaptive drug resistance, when bacteria lose biofilm protection, antibiotic 
susceptibility can be rapid (Walters et al., 2003). Chronic infections caused by $P$. aeruginosa have been found to be usually accompanied by biofilm formation (Hall and Mah, 2017). While the adaptive resistance mechanism of $P$. aeruginosa infection and recurrence is related to biofilmmediated resistance (Pang et al., 2019).

\subsection{Modification of Drug Targets}

\subsubsection{Methylation of 16S rRNA Ribosomal Subunit}

One mechanism of clinically significant drug resistance is acquired 16S rRNA methyltransferase, which adds methyl groups to specific residues in the $16 \mathrm{~S}$ rDNA site using S-adenosylmethionine (SAM) as a cofactor. Compared with the original 16S rRNA, the affinity of AGAs for 16S rRNA added with methyl groups is reduced, which confers high-level and broad-spectrum aminoglycoside resistance (Wachino et al., 2020).

16S-RMTases are divided into two categories: Those with the N7 position of methylated nucleotide G1405 and those with N1 position of methylated nucleotide A1408. Subsequently, a total of nine N7-G1405 16S-RMTases) were identified, which include ArmA, RmtA, RmtB (including RmtB1 and RmtB2 alleles), RmtC, RmtD (including RmtD1 and RmtD2 alleles), RmtE, $\mathrm{RmtF}, \mathrm{RmtG}$, and RmtH. These N7-G1405 16S-RMTases have moderate to high amino acid sequence similarity (Doi et al., 2016). However, N7-G1405 16S-RMTases are resistant to 4,6disubstituted 2-DOS, but not to 4,5-disubstituted 2-DOS and other AGAs, with ArmA, RmtB, and RmtC 16S-RMTases having a high level of resistance to 4,6-disubstituted 2-DOS AGAs. There is only $30 \%$ amino acid identity among the three enzymes; however, they show a high degree of three-dimensional structural similarity (Nosrati et al., 2019).

\subsection{2 rRNA Sequence Mutations}

Aminoglycoside resistance is usually not caused by bacterial target mutations, because most bacteria have more than one copy of the rRNA coding gene. To induce aminoglycoside resistance through this mechanism requires mutations in every gene copy (Serio et al., 2018). AGAs affect ribosome mutation to produce drug resistance via the rrs and tlyA genes. The rrs gene, encoding 16S rRNA (Honoré et al., 1995), and the tlyA gene, encoding a $2^{\prime}$-O-methyltransferase, an modifies nucleotide C1409 in Helix 44 of $16 \mathrm{~S}$ rRNA and nucleotide C1920 in Helix 69 of 23 S rRNA, respectively (Johansen et al., 2006). It was found that the most common mutations related to AGA resistance in clinically resistant mycobacterium tuberculosis were A1401G, C1402T, and G1484T in the rrs gene (Georghiou et al., 2012).

\subsubsection{Ribosomal Mutations}

The bacterial ribosome is composed of a small $30 \mathrm{~S}$ subunit composed of $16 \mathrm{~S}$ rRNA and 20 proteins, and a large 50S subunit composed of 23S rRNA, 5S rRNA and 34 proteins. AGAs bind to a region of the $16 \mathrm{~S}$ rRNA decoding region on the ribosome $30 \mathrm{~S}$ subunit, then disrupting the normal assembly of the protein, thereby finally affecting bacterial reproduction (Wilson, 2014).
Some 2-DOS AGAs such as gentamicin, neomycin B and paromomycin bind to the major groove of helix 69 (H69) of the $23 \mathrm{~S}$ rRNA of the $50 \mathrm{~S}$ large subunit, thereby affecting the translation on ribosomes (Wang et al., 2012; Wasserman et al., 2015). In AGA-resistant $P$. aeruginosa, changes in the ribosomal helix 69 conformation and deletion of the ribosomal protein UL6 will prevent them from binding to the translation initiation factor IF2, thus interfering with protein synthesis (Halfon et al., 2019).

\subsection{Changes of Bacterial Metabolism}

The carbon source and cellular respiration play important roles in bacterial pathogenicity and antibiotic sensitivity (Vitko et al., 2015; Vilchèze et al., 2017). Crc, Hfq and a small RNA CrcZ act as central regulators in carbon metabolism of $P$. aeruginosa. The catabolite repression control protein $(\mathrm{Crc})$ forms a complex with the RNA chaperone $\mathrm{Hfq}$, and directly inhibits the translation of catabolic genes via binding to the target mRNA (Sonnleitner et al., 2018). Hfq is considered critical for biofilm formation (Pusic et al., 2016), and also contributes to bacterial resistance to antibiotics such as gentamicin (Pusic et al., 2018).

The triphosphate isomerase, TpiA, can reversibly convert glyceraldehyde 3-phosphate to dihydroxyacetone phosphate, which is a key step linking glucose metabolism to glycerol and phospholipid metabolism. Mutations in the TpiA gene have been found to enhance carbon metabolism, respiration, and oxidative phosphorylation in bacteria, thereby increasing the membrane potential and promoting AGA uptake. Studies have found that the level and stability of $\mathrm{CrcZ}$ in bacteria with TpiA mutations are increased. $\mathrm{CrcZ}$ mutations can restore the expression of type III secretion system (T3SS) genes and enhance the resistance of bacteria to AGAs (Xia et al., 2020).

\section{STRATEGIES TO REVERSE BACTERIAL RESISTANCE TO AMINOGLYCOSIDE ANTIBIOTICS \\ 4.1 Structure Optimization and Modification Strategy of Aminoglycoside Antibiotics}

To solve the problem of resistance to AGAs, except the development of new antibiotics, structural modification of existing AGAs to restore their antibacterial activity remains an important way. In the case of Aminoglycoside modified enzymes, AMEs modification is one of the important mechanisms conferring resistance to AGAs in bacteria (Serpersu et al., 2008). There are genes encoding AMEs in the plasmid (Bassenden et al., 2016), while AMEs genes catalyze aminoglycoside hydroxyl or amine functionalities modification, rendering AGAs cannot bind to bacterial ribosomal targets, resulting in drug resistance (Ramirez and Tolmasky, 2010). For example, second-generation semi-synthetic AGAs derivatives have been designed with reference to the ribosome structure and the mechanism of AMEs, including dibekacin and amikacin modified from kanamycin; isepamicin and netilmicin modified from gentamicin; and sisomicin. At present, research is focusing on the third-generation AGAs that block the site of 
action of AMEs and have reduced side effects. Plazomicin (ACHN-490) is a modified sisomicin derivative; it was developed as an agent to avoid resistance via common AMEs (Dozzo and Moser, 2010). The general structure of AGAs is characterized by the presence of aminocyclic alcohol nuclei (cyclohexanes with or without substituted amino and hydroxyl groups), which are usually coupled to AGAs (Ramirez and Tolmasky, 2017). Plazomicin blocks the AME site of action through a series of structural modifications to enhance its antibacterial activity. As plazomicin lacks hydroxyl groups at the 3 and $4^{\prime}$ positions, it protects itself from modification of ANT $\left(4^{\prime}\right)$ and APH (3). The introduction of an unsaturated hydroxyethyl group at position $6^{\prime}-\mathrm{NH} 3$ can block the action site of AAC $\left(6^{\prime}\right)$. Plazomicin also has an N-1 substitution with 4-amino-2-hydroxybutanoic acid, which blocks AAC (3), ANT $\left(2^{\prime \prime}\right)$, and APH $\left(2^{\prime \prime}\right)$. These AMEs are often present in ESBLproducing and carbapenem-resistant Enterobacteriaceae, playing an important role in resistance to AGAs (Karpiuk and Tyski, 2015; Syue et al., 2016; Eljaaly et al., 2019).

\subsection{Synergistic Antibacterial Strategy of AGAs Combined With Other Drugs}

In addition to bacterial resistance, side effects of AGAs are another reason that hinders the clinical application of AGAs. The represent toxic side effects include ototoxicity caused by AGAs, cochlear nerve injury caused by ototoxicity and nephrotoxicity caused by proximal tubular epithelial cell injury (Kros and Steyger, 2019; Jospe-Kaufman et al., 2020; Rosenberg et al., 2020). However, the antibacterial effect of AGAs in combination with different compounds is better than that when the antibiotics are used alone. The investigation found that the combination cannot only exert a synergistic antibacterial effect but also reduce the dosage of the AGAs, leading to the reduced chance of occurrence and degree of side effects. Herein, synergistic antibacterial effects in combination with AGAs reported in recent years are summarized below.

\subsubsection{Combination With Compounds With Antibacterial Activities}

\subsubsection{Combination With Other Antibacterial Agents}

\subsection{Beta-Lactam Antibiotics}

Combinations of AGAs such as gentamicin can expand the scope of clinical treatment, accelerate bacterial clearance, and improve antibiotic resistance, especially the because of the synergistic antibacterial effects with $\beta$-lactam antibiotics (Le et al., 2011; Rhodes et al., 2017). $\beta$-lactam antibiotics cause non-fatal damage to the bacterial cell wall, thus promoting AGA entry inro bacteria and enhancing their killing ability (Davis, 1982). AGAs in combination with $\beta$-lactam antibiotics are commonly used in severe hospitalacquired infections by multidrug resistant species, such as acquired pneumonia, ventilator-associated pneumonia, and sepsis (Tamma et al., 2012; Sick et al., 2014; May 2016).

\subsection{Macrolides}

Azithromycin is the most commonly used macrolide in clinical practice, which has the advantages of strong antibacterial activity and a long half-life. AGAs and azithromycin are used widely to treat $P$. aeruginosa infections, and the combination of the two antibiotics can reduce the single-dose of each antibiotic. Studies have found that gentamicin can inhibit translation and increase the killing effect of azithromycin on planktonic and biofilm cells (Ren et al., 2019). Previous studies have shown that gentamicin or gemfloxacin, combined with azithromycin, has a significant effect on the treatment of genitourinary gonorrhea (Kirkcaldy et al., 2014).

\subsection{Polymyxins}

Polymyxins are one of the most commonly used drugs against gram-negative bacteria, especially against $P$. aeruginosa. The combination of a polymyxin and amikacin presented a synergistic antibacterial effect on polymyxin-sensitive and resistant $P$. aeruginosa. Polymyxin-sensitive P. aeruginosa (FADDI-PA111) and polymyxinresistant $P$. aeruginosa (LESB58) were selected for the combined antibacterial treatment with polymyxin $\mathrm{B}$ and amikacin. After their co-administration, a metabonomic analysis showed that the necessary bacterial membrane lipid levels involved in the biosynthesis of phospholipids and lipopolysaccharide (LPS) were reduced significantly, demonstrating that polymyxin B combined with amikacin could inhibit the intermediates in LPS synthesis significantly (Hussein et al., 2019). The pentose phosphate pathway (PPP) is the key source for the synthesis of LPS precursors, and the antibacterial effect might result from early inhibition of the PPP. The study also found that polymyxin B combined with amikacin interfered with the tricarboxylic acid (TCA) and glycolysis pathways in FADDIPA111, but this effect was not found in LESB58. Bacterial central carbohydrate metabolism, represented by glycolysis and TCA cycle, has been an important target in research into new antibiotics in recent years. The inhibitory effect of polymyxin B combined with amikacin on the pyridine nucleotide cycle (PNC) might also be one of the mechanisms of its synergistic antibacterial effect. The combined treatment resulted in a significant reduction of D-ribose-5phosphate, a key initial intermediate for purine and pyrimidine metabolism in FADDI-PA111, indicative of nucleotide degradation. The combination of the two drugs had a significant effect on the metabolism of arginine and proline in FADDI-PA111, leading to the destruction of amino acid pathways (Hussein et al., 2019). The disruption of amino acid pathways, represented by arginine metabolism, is considered to be a new way to deal with bacterial infection and destroy their mechanism of action (Xiong et al., 2016).

\subsection{Antimicrobial Peptides}

AMPs have emerged from their origins as antibiotics in nature and are widely distributed in animals and plants. They are the first line of defense against pathogens invading the body (Yeung et al., 2011). AMPs have the characteristics of broad-spectrum resistance, rapid action, and low resistance tendency. With the increasing resistance to existing antibiotics, AMPs are expected to become a more widely used class of antibacterial drugs (Wang et al., 2014). In the study of the synergistic antibacterial effect of antimicrobial peptide PMAP-36 or PRW4 combined with gentamicin against E. coli and $S$. aureus, it was found that AMPs and gentamicin had a synergistic (fractional lethal concentration $($ FLC $)<0.5)$ and a partial synergistic effect $(0.5$ 
$<$ FLC < 1) against E. coli and $S$. aureus, respectively. The synergistic antibacterial effect of gentamicin with PMAP-36 or PRW4 on gram-negative bacteria (E. coli) was found to be caused not only by the AMPs weakening the bacterial outer membrane and increase membrane permeability, so that gentamicin could more easily enter the cytoplasmic membrane, but also because of their direct antibacterial activity via interactions with intercellular targets, such as DNA, after entering the bacteria. The exact mechanism of AMPs in gram-positive bacteria is still unclear. Analyzing the molecular structure of the two AMPs, it was noted PMAP-36 is more hydrophobic than PRW4, and this hydrophobicity might promote membrane rupture and increase the antibacterial effect (Wang et al., 2014).

\subsubsection{Combination With Other Natural Plant Extracts With Antibacterial Activities}

Plant essential oil has antibacterial, synergistic antibacterial and other pharmacological effects; they are one of the important sources of natural medicine extracts (Bakkali et al., 2008). Therefore, during the development of higher antibacterial activity against a variety of gram-negative bacteria and grampositive bacterial infections with antibacterial drugs combined with plant essential oils, it was found that gentamicin combined with the essential oils extracted from Pelargonium graveolens and Aniba rosaeodora had synergistic effects. The combination can reduce the minimum effective dose of gentamicin. Especially in the essential oil of Acinetobacter baumannii, gentamicin combined with this had a significant synergistic antibacterial effect. The chemical composition of essential oils was studied using gas chromatographic analysis, which showed that the essential oils extracted from Pelargonium graveolens and Aniba rosaeodora contained a high percentage of terpene alcohols (Rosato et al., 2010). The antibacterial mechanism of monoterpenes was found to be due to the destruction of the microbial plasma membrane, resulting in changes in membrane permeability and intracellular substance efflux (Trombetta et al., 2005), such that a high content of terpene alcohols benefitted the antibacterial effect of gentamicin, mainly due to the blocking protein synthesis by binding to the $30 \mathrm{~S}$ subunit of the bacterial ribosome.

Camellia sinensis (green tea) has been proved to have a wide range of antibacterial activity. A study found a high content catechin especially epigallocatechingallate (EGCG) in green tea (Song and Seong, 2007). Studies have found that EGCG combined with gentamicin has a strong synergistic antibacterial effect against multi-drug resistant E.coli and $S$. aureus, because EGCG in green tea can destroy the bacterial cell membrane and eventually lead to bacterial rupture (Parvez et al., 2019).

Triphala, comprising the dried pericarp of the fruit of three plant from India, Myrobalans Terminalia chebula Retz. (Haritaki, Family: Combretaceae), Terminalia bellirica Roxb. (Bibhitaki, Family: Combretaceae), and Phyllanthus emblica Linn. or Emblica officinalis Gaertn. (Amalaki or the Indian gooseberry, Family: Euphorbiaceae), is an important medicine in the Indian traditional medicine system (Baliga, 2010; Baliga et al., 2012). Triphala and its single drug extracts have certain antibacterial activity against gram-negative and gram-positive bacteria (Srikumar et al., 2007; Tambekar and Dahikar, 2011; Parveen et al., 2018). Its phenolic content is closely related to its antibacterial activity (Bag et al., 2013). A study showed that gentamicin and triphala have a synergistic antibacterial effect on some multidrug resistant gram-negative bacilli. Phenolic compounds can destroy the cell membrane of the bacteria, thus, in the synergistic antibacterial effect of gentamicin and triphala. The mechanism may be similar to the synergistic effect of gentamicin and $\beta$-lactam antibiotics (Manoraj et al., 2019).

Brazilian red propolis contains a large number of phenolic compounds, of which the largest proportion is flavonoids, which are believed to be related to the antibacterial effect of red propolis (F. B. Carvalho et al., 2016; da Cruz Almeida et al., 2017). Previous studies have found that combinations of antibiotics with phenolic compounds cause damage to the bacterial cell wall or cell membrane and enhance antibiotic activity (Mun et al., 2013; Guo et al., 2015), making it easier for antibiotics to enter the interior of the bacterial cell. This might be the main mechanism of action by which propolis compounds enhance antibiotic activity (Orsi et al., 2012). Studies have reported the synergistic effect of gentamicin or imipenem combined with Brazilian red propolis on $S$. aureus and $P$. aeruginosa, and discovered the effect of seasonal humidity changes on resin plants: The levels of active ingredients in propolis in specimens collected in dry season period were obviously higher than those in specimens collected in the rainy season. Therefore, the study found that the combination of propolis collected in the drier period and gentamicin or imipenem has a synergistic effect (Regueira et al., 2017).

5-hydroxy-3,7,4-trimethoxyflavone (VG.EF.CLII) was isolated from Vitex gardneriana leaves. Nuclear magnetic resonance analysis found that the isolated 5-hydroxy-3,7,4 trimethoxyflavone had the chemical formula $\mathrm{C}_{18} \mathrm{H}_{16} \mathrm{O}_{6}$. To study its antibacterial activity against $E$. coli and $S$. aureus, the minimum inhibitory concentration (MIC) was used to evaluate the antibacterial effect of the component and its ability to regulate the activity of antibiotics. VG.EF.CLII showed antibacterial activity against multidrug resistant bacterial strains. When combined with the antibiotics norfloxacin and gentamicin, respectively, and tested against 27 strains of E. coli and 358 strains of $S$. aureus isolated from surgical wounds, VG.EF.CLII had a significant synergistic antibacterial effect (Macedo et al., 2019).

\subsubsection{Combination With Other Compounds or Materials Without Antibacterial Activity} 4.2.2.1 Combination With Anti-Inflammatory Analgesics

Periprosthetic joint infection (PJI) is a serious complication of total joint replacement. Antibacterial drugs, generally gentamicin, tobramycin and vancomycin, are chosen for local and systemic administration against PJI (Hickson et al., 2015; Vrabec et al., 2016). Some analgesics have been found to also possess certain antibacterial activity against a variety of pathogens (Johnson et al., 2008). Several types of analgesics, such as sodium channel 
blockers, non-steroidal anti-inflammatory drugs (NSAIDs) and opioids, are used in pain management after arthroplasty (Imani, 2011). The synergistic antibacterial effects of bupivacaine, lidocaine (sodium channel blocker) and ketorolac (NSAID) in combination with gentamicin (broad-spectrum antibiotic) against $S$. aureus were assessed. The results showed that the fractional inhibitory concentration index (FICI) of the combination of ketorolac and gentamicin was lower than 0.4 , indicating that the combination had a synergistic antibacterial effect (Gil et al., 2020).

In multidrug-resistant bacteria, other non-antibiotic drugs can be used in combination with drug-resistant antibiotics to regain the antibacterial effect (Cai et al., 2007; Chan et al., 2017). In addition to the common anti-inflammatory, analgesic, and antipyretic effects of NSAIDs, there are also reports showing that they have a synergistic effect on the antibacterial activity of antibiotics (Yin et al., 2014; Obad et al., 2015; Chan et al., 2017). A study found that in the treatment of MRSA infections using NSAIDs combined with drug-resistant antibiotics, it was found that Meloxicam had a partial synergistic effect with oxytetracycline and gentamicin. In addition, Flunixin Meglumine had a synergistic effect with oxytetracycline and a partial synergistic effect with gentamicin; however, the mechanism of action needs further study (Altaf et al., 2019).

\subsubsection{Combination With and Natural Plant Extracts Without Antibacterial Activities}

As mentioned above, plant essential oils have antibacterial, synergistic antibacterial and other pharmacological effects. Although the essential oil of Mikania cordifolia (EOMc) and its major constituent, limonene, has no direct antibacterial activity, it can reverse antibiotic resistance by regulating the action of antibiotics. For P. aeruginosa, EOMc combined with gentamicin and norfloxacin displayed a synergistic antibacterial effect; and for S. aureus, EOMc reduced the MIC of gentamicin toward bacteria (Justino de Araújo et al., 2020).

Considering that saponins can alter the local chemical environment of the cell membrane and may alter how bacteria absorb or act on antibiotics, the combination of glycyrrhizic acid and gentamicin was found to have therapeutic potential against local bacterial infections caused by vancomycin-resistant enterococci (Schmidt et al., 2016). The Chinese herbal compound, plumbagin, stimulates the uptake of gentamicin by carbapenem-resistant klebsiella pneumonia (CRKp) by enhancing the efflux of the TCA cycle and the proton-motive force to achieve synergistic antibacterial activity. It can be combined with aminoglycoside antibiotics to enhance its efficacy and reduce its dosage (Chen et al., 2020).

Croton ceanothifolius essential oil (CcEO) can enhance the antibacterial activity of gentamicin and norfloxacin against $E$. coli, $S$. aureus, and $P$. aeruginosa. The presence of the two antibiotics acting within the bacterial cell indicated that the CcEO promotes the penetration of antibiotics into the bacterial cytoplasm and thus exerts a synergistic effect. By measuring the MIC of CcEO against multidrug resistant bacteria, it was found that the MIC was greater than $1,024 \mu \mathrm{g} / \mathrm{ml}$ in all strains, indicating that CcEO has no antibacterial activity. CcEO was analyzed by gas chromatography-mass spectrometry (GC/MS), and a total of 25 chemical components were identified. The main ingredients include bicyclogermacrene (26.3\%), germanene D (14.7\%), and E-caryophyllene (11.7\%). The authors hypothesized that although CcEO cannot exert a direct antibacterial effect, it can synergistically enhance the effect of antibiotics on membrane permeability (Araújo et al., 2020).

Kaempferol 7-O- $\beta$-D-(6"-O -cumaroyl)-glucopyranoside flavonoids were isolated from croton leaves and studied for their antibacterial and synergistic antibacterial effects. It was found that although it did not have direct antibacterial activity against $S$. aureus, E. coli, and P. aeruginosa, when kaempferol 7$\mathrm{O}-\beta$-D-(6"-O-cumaroyl)-glucopyranoside at $128 \mu \mathrm{g} / \mathrm{ml}$ was combined with gentamicin, it showed a synergistic antibacterial effect on both $S$. aureus and E. coli (Cruz et al., 2020). The hydroxyphenyl groups in flavonoids have affinity for proteins; therefore, these compounds act as inhibitors of bacterial enzymes and interfere with their synthesis pathways (Alcaráz et al., 2000).

The Hexanic Zea Mays L. Silk Extract (Poaceae or HEZN) is used widely in Brazilian folk medicine to treat genitourinary tract diseases. A study used standard E. coli ATCC 25922, S. aureus ATCC 25923 and $P$. aeruginosa ATCC 27853 strains, as well as 27 multi-resistant strains of E. coli, 35 strains of S. aureus, and 31 strains of $P$. aeruginosa. The authors found that HEZM and its metabolites had an MIC $\geq 1,024 \mu \mathrm{g} / \mathrm{ml}$ for all tested strains, indicating that at least for these strains, HEZM and its metabolites have no obvious antibacterial activity. In order to study the regulatory effect of HEZM on antibiotics, a subinhibitory concentration (MIC/8) combined with amikacin and gentamicin was selected to test the resistance of multiple drug-resistant strains. In $S$. aureus and P. aeruginosa, HEZM combined with amikacin and gentamicin reduced the MICs of the antibiotics significantly. However, the binding of the extract with amikacin against E. coli significantly increased the MIC of this antibiotic, indicating that HEZM antagonized the effect of the antibiotic (A. B. L. Carvalho et al., 2019). Phytochemical analysis of HEZM revealed that it contained four types of important secondary metabolites, including: tannins, flavonoids, flavonols, and xanthones (A. B. L. Carvalho et al., 2019). Flavonoids, as common extracts in natural plants, are most frequently related to the synergistic effects of natural products. One of the classes of metabolites in the extract is xanthones, and a subgroup of xanthones, called oxygenated xanthones, can increase the solubility of cell membranes to exert antibacterial activity in norfloxacin-resistant S. aureus (Xiao et al., 2008). Studies have found that the effects of HEZM on AGAs are different in different gram-negative and gram-positive bacteria. The structural differences between gram-negative and gram-positive bacteria might also determine the effect of natural extracts on antibiotics (A. B. L. Carvalho et al., 2019).

\subsubsection{Combination With Nanomaterials}

Nanomaterials especially silver nanoparticles (AgNPs) have a synergistic antibacterial effect when combined with antibiotics (Hajipour et al., 2012; Singh et al., 2015). Reactive oxygen species (ROS) production is a common mechanism by which antibiotics 
cause bacterial cell death (Kohanski et al., 2007; Kim et al., 2011). Studies have found that gentamicin significantly enhanced the generation of ROS by AgNPs. Luminol chemiluminescence (CL) proved that the antibacterial activity of Tween-stabilized AgNPs is accompanied by the production of ROS. Gentamicin combined with Tween-stabilized AgNPs showed synergistic antibacterial activity against gentamicin-resistant staphylococcus epidermidis (Mazur et al., 2020). AgNPs combined with antibiotics can kill bacteria via different mechanisms, thereby playing a synergistic antibacterial effect (Sukhorukova et al., 2018). It has been reported that AgNPs have the ability to penetrate the bacterial cell wall, destroy the cell membrane, and cause the death of the bacteria. In E. faecalis (Ef) infection, we also tested the synergistic antibacterial effect of multiple antibiotics and AgNPs, and found that the synergistic antibacterial effect of gentamicin and chloramphenicol combined with AgNPs was significant (Katva et al., 2018).

Graphene is a biocompatible material with biocarrier, cancer therapy, biosensing and antibacterial activities (Zhou et al., 2009; Yang et al., 2010; Zhang et al., 2010; Liu et al., 2011). In the study of the antibacterial effect of water-soluble TOB-GO-Ag composite composed of aminoglycoside antibiotics (tobramycin), Graphene oxide (GO) and AgNPs against multidrug-resistant gram-negative E. coli, it was found that compared with GO, AgNPs and tobramycin, TOB-GO-Ag showed the highest antibacterial activity. The research of the mechanism by which TOB-GO-Ag composite exerted a synergistic antibacterial effect via destroying the integrity of the cell wall and promoting the entry of $\mathrm{Ag}^{+}$ion and GO into cells, which finally destroyed bacteria through oxidative stress mechanism. Meanwhile tobramycin in the prepared composites could also help affect bacterial growth by inhibiting protein synthesis (Ullah et al., 2018).

Some bismuth (Bi)-containing compounds have been reported to have synergistic antibacterial effects toward bacteria when used in combination with antibiotics (Keogan and Griffith, 2014). The study found that the MIC values of $\mathrm{Bi}_{2} \mathrm{~S}_{3}$ nanoparticles against $S$. aureus and MRSA are all $>1,024 \mu \mathrm{g} / \mathrm{ml}$, indicating that $\mathrm{Bi}_{2} \mathrm{~S}_{3}$ has no antibacterial activity against these two bacteria, but combined with gentamicin has a synergistic antibacterial effect in MRSA. The synergistic antibacterial mechanism was mainly related to the interaction between $\mathrm{Bi}_{2} \mathrm{~S}_{3}$ and gentamicin, the destruction of bacterial cell membrane, the increase of gentamicin content in bacteria and the generation of ROS in bacteria (Ma et al., 2017).

$\mathrm{CaCO}_{3}$ nanoparticles (CCNPs) have a relatively regular chain structure, and the crystal grain size is about $62.5 \mathrm{~nm}$. Studies have found that CCNPs can carry gentamicin and prolong the release time of gentamicin; so that the complete release time of gentamicin can be extended to $24 \mathrm{~h}$. CCNPs can improve the antibacterial activity of gentamicin significantly. Zeta potential analysis and microscopic observations showed that CCNPs adsorbed on the surface of bacteria increased the degree of damage to the bacterial cell wall, enhanced the permeability of the cell membrane, leading to the increased bacterial death (Pan et al., 2017).

\subsubsection{Combination With Photosensitizers}

Some antibiotics combined with photosensitizer-mediated photodynamic antimicrobial chemotherapy (PACT) have been found to be with better antibacterial effects against bacteria (Branco et al., 2018; Pérez-Laguna et al., 2018; Tavares et al., 2018). PACT mediated by photosensitizers will produce ROS under specific wavelength light stimulation, which induces phototoxic damage to bacteria (Pérez-Laguna et al., 2019). PACT is not limited to its antibiotic resistance pattern to eliminate microorganisms and is also effective against microorganisms in a biofilm state (Giuliani, 2014; García et al., 2015).

Rose bengal (RB) is a xanthine dye used as a photosensitizer for PACT (Pérez-Laguna et al., 2017). The study found that RBPACT combined with gentamicin has a synergistic antibacterial effect on planktonic $S$. aureus, while a synergistic effect is observed only when the maximum concentration tested of RBPACT and gentamicin $(64 \mu \mathrm{g} / \mathrm{ml}$ and $40 \mu \mathrm{g} / \mathrm{ml}$, respectively) was used in biofilm (Pérez-Laguna et al., 2018). Its mechanism of synergistic antibacterial effect is considered to be that after PACT damages cells, it promotes the entry of gentamicin into bacteria, and gentamicin binds to the $30 \mathrm{~S}$ subunit of the bacterial ribosome to impair protein synthesis, resulting in bacterial death (Barra et al., 2015; Pérez-Laguna et al., 2018).

The photobacterial agent toluidine blue (TB) is a hydrophilic cationic alkaline photosensitizer (PS). TB has high affinity for bacterial membranes and is believed to cause membrane damage (Wainwright et al., 2016). Further studies found that TB-PACT combined with gentamicin had a more significant synergistic antibacterial effect against $S$. aureus and MRSA than either treatment alone (Liu et al., 2020). Antimicrobial photodynamic therapy (aPDT) is considered to promote the passage of antibacterial drugs by destroying the outer membrane of bacterial cells using light irradiation. Blue light-emitting diode (LED) light irradiation affects the growth of both gram-negative and gram-positive bacteria.

When blue LED light was used in combination with the AGAs such as amikacin and gentamicin, it showed a synergistic antibacterial effect on E. coli and S. aureus, and promoted the inactivation of the bacteria, which might be attributed to the antibacterial effect induced by oxidative stress (Silva et al., 2019).

\section{CONCLUSION}

AGAs are widely used in clinical practice due to their advantages of good water solubility, broad antibacterial spectrum and strong antibacterial activities. With its wide applications, the appearance of side effects as well as the increasingly bacterial resistance has restricted their clinical application. In recent years, based on continuous research on AGAs providing a deeper understanding of the antibacterial mechanism of action and the resistance mechanism, the strategies to reverse bacterial resistance to AGAs is developing. The strategies include structural modification of older AGAs based on new target prediction of existing 
AGAs, hoping to restore their antibacterial activity and presenting the new charm of existing AGAs.

AGAs in combined with other antibacterial, antiinflammatory, and analgesic drugs, natural plant extracts, and other ingredients have a synergistic antibacterial effect that allows reduction the dosage of single drugs and exert good antibacterial activity with lower side effects. Because many drugs with theoretical basis have synergistic antibacterial effect in the experimental stage, drug combinations are expected to improve the increasingly severe bacterial drug resistance, thereby ensuring a bright future for AGAs.

The combination of antibiotics and other drugs is an important strategy to overcome bacterial resistance. We hope that the prediction of the old AGAs drug targets and the investigation of the important mechanisms of bacterial growth will lay a foundation for finding new AGAs derivatives and compounds combined with AGAs.

\section{REFERENCES}

Aggen, J. B., Armstrong, E. S., Goldblum, A. A., Dozzo, P., Linsell, M. S., Gliedt, M. J., et al. (2010). Synthesis and Spectrum of the Neoglycoside ACHN-490. Antimicrob. Agents Chemother. 54 (11), 4636-4642. doi:10.1128/aac.00572-10

Alcaráz, L. E., Blanco, S. E., Puig, O. N., Tomás, F., and Ferretti, F. H. (2000). Antibacterial Activity of Flavonoids against Methicillin-Resistant Staphylococcus aureus Strains. J. Theor. Biol. 205 (2), 231-240. doi:10.1006/ jtbi.2000.2062

Almaghrabi, R., Clancy, C. J., Doi, Y., Hao, B., Chen, L., Shields, R. K., et al. (2014). Carbapenem-resistant Klebsiella pneumoniae Strains Exhibit Diversity in Aminoglycoside-Modifying Enzymes, Which Exert Differing Effects on Plazomicin and Other Agents. Antimicrob. Agents Chemother. 58 (8), 4443-4451. doi:10.1128/aac.00099-14

Altaf, M., Ijaz, M., Ghaffar, A., Rehman, A., and Avais, M. (2019). Antibiotic Susceptibility Profile and Synergistic Effect of Non-steroidal Anti-inflammatory Drugs on Antibacterial Activity of Resistant Antibiotics (Oxytetracycline and Gentamicin) against Methicillin Resistant Staphylococcus aureus (MRSA). Microb. Pathog. 137, 103755. doi:10.1016/j.micpath.2019.103755

Antibiotic resistance threats in the United States, 2019 (2019). Antibiotic Resistance Threats in the United States, 2019. Retrieved from https://stacks. cdc.gov/view/cdc/82532.

Araújo, A. C. J., Freitas, P. R., Rodrigues Dos Santos Barbosa, C., Muniz, D. F., Esmeraldo Rocha, J., Neto, J. B. A., et al. (2020). Essential Oil of Croton Ceanothifolius Baill. Potentiates the Effect of Antibiotics against Multiresistant Bacteria. Antibiotics (Basel) 9 (1). doi:10.3390/antibiotics 9010027

Bafna, J. A., Sans-Serramitjana, E., Acosta-Gutiérrez, S., Bodrenko, I. V., Hörömpöli, D., Berscheid, A., et al. (2020). Kanamycin Uptake into Escherichia coli Is Facilitated by OmpF and OmpC Porin Channels Located in the Outer Membrane. ACS Infect. Dis. 6 (7), 1855-1865. doi:10.1021/ acsinfecdis.0c00102

Bag, A., Bhattacharyya, S. K., and Pal, N. K. (2013). Antibacterial Potential of Hydroalcoholic Extracts of Triphala Components against Multidrug-Resistant Uropathogenic Bacteria-Aa Preliminary Report. Indian J. Exp. Biol. 51 (9), 709-714.

Bakkali, F., Averbeck, S., Averbeck, D., and Idaomar, M. (2008). Biological Effects of Essential Oils-Aa Review. Food Chem. Toxicol. 46 (2), 446-475. doi:10.1016/j. fct.2007.09.106

Baliga, M. S., Meera, S., Mathai, B., Rai, M. P., Pawar, V., and Palatty, P. L. (2012). Scientific Validation of the Ethnomedicinal Properties of the Ayurvedic Drug Triphala: a Review. Chin. J. Integr. Med. 18 (12), 946-954. doi:10.1007/s11655012-1299-x

Baliga, M. S. (2010). Triphala, Ayurvedic Formulation for Treating and Preventing Cancer: a Review. J. Altern. Complement. Med. 16 (12), 1301-1308. doi:10.1089/ acm.2009.0633

\section{AUTHOR CONTRIBUTIONS}

$\mathrm{HZ}$ conceived and designed the conception of review article, and made the amendments of the manuscript. NW reviewed the relevant literature and wrote the manuscript. JL, FD, and YH supplemented the content of the manuscript. All authors read, revised and approved the final manuscript.

\section{FUNDING}

This work was supported by the National Natural Science Foundation of China-Guizhou Provincial People's Government Joint Fund Project, sub-project (No. U1812403-4-1) and the fourth batch of "Thousand People Innovation and Entrepreneurship Talents Fund" in Guizhou Province.

Barra, F., Roscetto, E., Soriano, A. A., Vollaro, A., Postiglione, I., Pierantoni, G. M., et al. (2015). Photodynamic and Antibiotic Therapy in Combination to Fight Biofilms and Resistant Surface Bacterial Infections. Int. J. Mol. Sci. 16 (9), 20417-20430. doi:10.3390/ijms160920417

Bassenden, A. V., Rodionov, D., Shi, K., and Berghuis, A. M. (2016). Structural Analysis of the Tobramycin and Gentamicin Clinical Resistome Reveals Limitations for Next-Generation Aminoglycoside Design. ACS Chem. Biol. 11 (5), 1339-1346. doi:10.1021/acschembio.5b01070

Becker, B., and Cooper, M. A. (2013). Aminoglycoside Antibiotics in the 21st century. ACS Chem. Biol. 8 (1), 105-115. doi:10.1021/cb3005116

Branco, T. M., Valério, N. C., Jesus, V. I. R., Dias, C. J., Neves, M. G. P. M. S., Faustino, M. A. F., et al. (2018). Single and Combined Effects of Photodynamic Therapy and Antibiotics to Inactivate Staphylococcus aureus on Skin. Photodiagnosis Photodyn Ther. 21, 285-293. doi:10. 1016/j.pdpdt.2018.01.001

Cai, Y., Wang, R., Pei, F., and Liang, B. B. (2007). Antibacterial Activity of Allicin Alone and in Combination with Beta-Lactams against Staphylococcus Spp. And Pseudomonas aeruginosa. J. Antibiot. (Tokyo) 60 (5), 335-338. doi:10.1038/ja. 2007.45

Carvalho, A. B. L., Cruz, C. A., Freitas, C. L. A., Aguiar, J. J. D. S., Nunes, P. L. W. S., Lima, V. M. D. S., et al. (2019). Chemical Profile, Antibacterial Activity and Antibiotic-Modulating Effect of the Hexanic Zea Mays L. Silk Extract (Poaceae). Antibiotics (Basel) 8 (1). doi:10.3390/antibiotics8010022

Carvalho, F. B., Boligon, A. A., Athayde, M. L., Rubin, M. A., Ferreira, J., and Trevisan, G. (2016). Inhibitory Effect of Scutia Buxifolia Extracts, Fractions, and Ursolic Acid on $\mathrm{Na}(+), \mathrm{K}(+)$-ATPase Activity In Vitro in Membranes Purified from Rat Hearts. J. Ethnopharmacol 179, 45-54. doi:10.1016/j.jep.2015.12.035

Castanheira, M., Davis, A. P., Mendes, R. E., Serio, A. W., Krause, K. M., and Flamm, R. K. (2018). In Vitro Activity of Plazomicin against Gram-Negative and Gram-Positive Isolates Collected from U.S. Hospitals and Comparative Activities of Aminoglycosides against Carbapenem-Resistant Enterobacteriaceae and Isolates Carrying Carbapenemase Genes. Antimicrob. Agents Chemother. 62 (8). doi:10.1128/aac.00313-18

Centrón, D., and Roy, P. H. (2002). Presence of a Group II Intron in a Multiresistant Serratia marcescens Strain that Harbors Three Integrons and a Novel Gene Fusion. Antimicrob. Agents Chemother. 46 (5), 1402-1409. doi:10. 1128/aac.46.5.1402-1409.2002

Chan, E. W. L., Yee, Z. Y., Raja, I., and Yap, J. K. Y. (2017). Synergistic Effect of Non-steroidal Anti-inflammatory Drugs (NSAIDs) on Antibacterial Activity of Cefuroxime and Chloramphenicol against Methicillin-Resistant Staphylococcus aureus. J. Glob. Antimicrob. Resist. 10, 70-74. doi:10.1016/j.jgar.2017.03.012

Chen, X., Yin, L., Peng, L., Liang, Y., Lv, H., and Ma, T. (2020). Synergistic Effect and Mechanism of Plumbagin with Gentamicin against Carbapenem-Resistant Klebsiella pneumoniae. Infect. Drug Resist. 13, 2751-2759. doi:10.2147/idr. S265753 
Clark, J. A., and Burgess, D. S. (2020). Plazomicin: a New Aminoglycoside in the Fight against Antimicrobial Resistance. Ther. Adv. Infect. Dis. 7, 2049936120952604. doi:10.1177/2049936120952604

Cruz, B. G., Dos Santos, H. S., Bandeira, P. N., Rodrigues, T. H. S., Matos, M. G. C., Nascimento, M. F., et al. (2020). Evaluation of Antibacterial and Enhancement of Antibiotic Action by the Flavonoid Kaempferol 7-O- $\beta$-D-(6"-O-Cumaroyl)Glucopyranoside Isolated from Croton Piauhiensis Müll. Microb. Pathog. 143, 104144. doi:10.1016/j.micpath.2020.104144

da Cruz Almeida, E. T., da Silva, M. C. D., Oliveira, J. M. D. S., Kamiya, R. U., Arruda, R. E. D. S., Vieira, D. A., et al. (2017). Chemical and Microbiological Characterization of Tinctures and Microcapsules Loaded with Brazilian Red Propolis Extract. J. Pharm. Anal. 7 (5), 280-287. doi:10.1016/j.jpha.2017.03.004

Daly, M., Villa, L., Pezzella, C., Fanning, S., and Carattoli, A. (2005). Comparison of Multidrug Resistance Gene Regions between Two Geographically Unrelated Salmonella Serotypes. J. Antimicrob. Chemother. 55 (4), 558-561. doi:10.1093/ jac/dki015

Das, T., Sehar, S., and Manefield, M. (2013). The Roles of Extracellular DNA in the Structural Integrity of Extracellular Polymeric Substance and Bacterial Biofilm Development. Environ. Microbiol. Rep. 5 (6), 778-786. doi:10.1111/1758-2229. 12085

Davis, B. D. (1982). Bactericidal Synergism between Beta-Lactams and Aminoglycosides: Mechanism and Possible Therapeutic Implications. Rev. Infect. Dis. 4 (2), 237-245. doi:10.1093/clinids/4.2.237

Degtyareva, N. N., Gong, C., Story, S., Levinson, N. S., Oyelere, A. K., Green, K. D., et al. (2017). Antimicrobial Activity, AME Resistance, and A-Site Binding Studies of Anthraquinone-Neomycin Conjugates. ACS Infect. Dis. 3 (3), 206-215. doi:10.1021/acsinfecdis.6b00176

Doi, Y., Wachino, J. I., and Arakawa, Y. (2016). Aminoglycoside Resistance: The Emergence of Acquired 16S Ribosomal RNA Methyltransferases. Infect. Dis. Clin. North. Am. 30 (2), 523-537. doi:10.1016/j.idc.2016.02.011

Dozzo, P., and Moser, H. E. (2010). New Aminoglycoside Antibiotics. Expert Opin. Ther. Pat 20 (10), 1321-1341. doi:10.1517/13543776.2010.506189

Eljaaly, K., Alharbi, A., Alshehri, S., Ortwine, J. K., and Pogue, J. M. (2019). Plazomicin: A Novel Aminoglycoside for the Treatment of Resistant Gram-Negative Bacterial Infections. Drugs 79 (3), 243-269. doi:10.1007/s40265-019-1054-3

Evangelisti, E., Yunusov, T., Shenhav, L., and Schornack, S. (2019). $\mathrm{N}$-acetyltransferase AAC(3)-I Confers Gentamicin Resistance to Phytophthora Palmivora and Phytophthora Infestans. BMC Microbiol. 19 (1), 265. doi:10.1186/s12866-019-1642-0

García, I., Ballesta, S., Gilaberte, Y., Rezusta, A., and Pascual, Á. (2015). Antimicrobial Photodynamic Activity of Hypericin against MethicillinSusceptible and Resistant Staphylococcus aureus Biofilms. Future Microbiol. 10 (3), 347-356. doi:10.2217/fmb.14.114

Garneau-Tsodikova, S., and Labby, K. J. (2016). Mechanisms of Resistance to Aminoglycoside Antibiotics: Overview and Perspectives. Medchemcomm 7 (1), 11-27. doi:10.1039/c5md00344j

Georghiou, S. B., Magana, M., Garfein, R. S., Catanzaro, D. G., Catanzaro, A., and Rodwell, T. C. (2012). Evaluation of Genetic Mutations Associated with Mycobacterium tuberculosis Resistance to Amikacin, Kanamycin and Capreomycin: a Systematic Review. PLoS One 7 (3), e33275. doi:10.1371/ journal.pone.0033275

Gil, D., Daffinee, K., Friedman, R., Bhushan, B., Muratoglu, O. K., LaPlante, K., et al. (2020). Synergistic Antibacterial Effects of Analgesics and Antibiotics against Staphylococcus aureus. Diagn. Microbiol. Infect. Dis. 96 (4), 114967. doi:10.1016/j.diagmicrobio.2019.114967

Giuliani, F. (2014). Photodynamic Therapy as a Novel Antimicrobial Strategy against Biofilm-Based Nosocomial Infections: Study Protocols. Methods Mol. Biol. 1147, 287-298. doi:10.1007/978-1-4939-0467-9_21

Gordon, L., Cloeckaert, A., Doublet, B., Schwarz, S., Bouju-Albert, A., Ganière, J. P., et al. (2008). Complete Sequence of the floR-Carrying Multiresistance Plasmid pAB5S9 from Freshwater Aeromonas Bestiarum. J. Antimicrob. Chemother. 62 (1), 65-71. doi:10.1093/jac/dkn166

Guo, X. F., Yang, Z. R., Wang, J., Lei, X. F., Lv, X. G., and Dong, W. G. (2015). Synergistic Antitumor Effect of Puerarin Combined with 5-fluorouracil on Gastric Carcinoma. Mol. Med. Rep. 11 (4), 2562-2568. doi:10.3892/mmr.2014. 3016

Haedersdal, M., Erlendsson, A. M., Paasch, U., and Anderson, R. R. (2016). Translational Medicine in the Field of Ablative Fractional Laser (AFXL)- assisted Drug Delivery: A Critical Review from Basics to Current Clinical Status. J. Am. Acad. Dermatol. 74 (5), 981-1004. doi:10.1016/j.jaad.2015.12.008 Hajipour, M. J., Fromm, K. M., Ashkarran, A. A., Jimenez de Aberasturi, D., de Larramendi, I. R., Rojo, T., et al. (2012). Antibacterial Properties of Nanoparticles. Trends Biotechnol. 30 (10), 499-511. doi:10.1016/j.tibtech. 2012.06.004

Halfon, Y., Jimenez-Fernandez, A., La Rosa, R., Espinosa Portero, R., Krogh Johansen, H., Matzov, D., et al. (2019). Structure of Pseudomonas aeruginosa Ribosomes from an Aminoglycoside-Resistant Clinical Isolate. Proc. Natl. Acad. Sci. U S A. 116 (44), 22275-22281. doi:10.1073/pnas. 1909831116

Hall, C. W., and Mah, T. F. (2017). Molecular Mechanisms of Biofilm-Based Antibiotic Resistance and Tolerance in Pathogenic Bacteria. FEMS Microbiol. Rev. 41 (3), 276-301. doi:10.1093/femsre/fux010

Herzog, I. M., Green, K. D., Berkov-Zrihen, Y., Feldman, M., Vidavski, R. R., EldarBoock, A., et al. (2012). 6"-Thioether Tobramycin Analogues: towards Selective Targeting of Bacterial Membranes. Angew. Chem. Int. Ed. Engl. 51 (23), 5652-5656. doi:10.1002/anie.201200761

Hickson, C. J., Metcalfe, D., Elgohari, S., Oswald, T., Masters, J. P., Rymaszewska, M., et al. (2015). Prophylactic Antibiotics in Elective Hip and Knee Arthroplasty: an Analysis of Organisms Reported to Cause Infections and National Survey of Clinical Practice. Bone Jt. Res 4 (11), 181-189. doi:10.1302/ 2046-3758.411.2000432

Hinz, A., Lee, S., Jacoby, K., and Manoil, C. (2011). Membrane Proteases and Aminoglycoside Antibiotic Resistance. J. Bacteriol. 193 (18), 4790-4797. doi:10. 1128/jb.05133-11

Holbrook, S. Y. L., and Garneau-Tsodikova, S. (2018). Evaluation of Aminoglycoside and Carbapenem Resistance in a Collection of DrugResistant Pseudomonas aeruginosa Clinical Isolates. Microb. Drug Resist. 24 (7), 1020-1030. doi:10.1089/mdr.2017.0101

Honoré, N., Marchal, G., and Cole, S. T. (1995). Novel Mutation in 16S rRNA Associated with Streptomycin Dependence in Mycobacterium tuberculosis. Antimicrob. Agents Chemother. 39 (3), 769-770. doi:10.1128/aac.39.3.769

Hu, F., Guo, Y., Zhu, D., Wanf, F., Jiang, X., Xu, Y., et al. (2021). CHINET Surveillance of Bacterial Resistance: Results of 2020. Chin. J. Infect. Chemother. 21 (04), 377-387. doi:10.16718/j.1009-7708.2021.04.001

Humphries, R., Bobenchik, A. M., Hindler, J. A., and Schuetz, A. N. (2021). Overview of Changes to the Clinical and Laboratory Standards Institute Performance Standards for Antimicrobial Susceptibility Testing, M100, 31st Edition. J. Clin. Microbiol. 59, Jcm0021321. doi:10.1128/jcm. 00213-21

Hussein, M., Han, M. L., Zhu, Y., Zhou, Q., Lin, Y. W., Hancock, R. E. W., et al. (2019). Metabolomics Study of the Synergistic Killing of Polymyxin B in Combination with Amikacin against Polymyxin-Susceptible and -Resistant Pseudomonas aeruginosa. Antimicrob. Agents Chemother. 64 (1). doi:10. 1128/aac.01587-19

Imani, F. (2011). Postoperative Pain Management. Anesth. Pain 1 (1), 6-7. doi:10. 5812/kowsar.22287523.181010.5812/aapm.1810

Johansen, S. K., Maus, C. E., Plikaytis, B. B., and Douthwaite, S. (2006). Capreomycin Binds across the Ribosomal Subunit Interface Using tlyAEncoded 2'-O-Methylations in $16 \mathrm{~S}$ and $23 \mathrm{~S}$ rRNAs. Mol. Cell 23 (2), 173-182. doi:10.1016/j.molcel.2006.05.044

Johnson, S. M., Saint John, B. E., and Dine, A. P. (2008). Local Anesthetics as Antimicrobial Agents: a Review. Surg. Infect. (Larchmt) 9 (2), 205-213. doi:10. 1089/sur.2007.036

Johnston, N. J., Mukhtar, T. A., and Wright, G. D. (2002). Streptogramin Antibiotics: Mode of Action and Resistance. Curr. Drug Targets 3 (4), 335-344. doi:10.2174/1389450023347678

Jospe-Kaufman, M., Siomin, L., and Fridman, M. (2020). The Relationship between the Structure and Toxicity of Aminoglycoside Antibiotics. Bioorg. Med. Chem. Lett. 30 (13), 127218. doi:10.1016/j.bmcl.2020.127218

Justino de Araújo, A. C., Freitas, P. R., Rodrigues Dos Santos Barbosa, C., Muniz, D. F., Rocha, J. E., Albuquerque da Silva, A. C., et al. (2020). GC-MS-FID Characterization and Antibacterial Activity of the Mikania Cordifolia Essential Oil and Limonene against MDR Strains. Food Chem. Toxicol. 136, 111023. doi:10.1016/j.fct.2019.111023

Karpiuk, I., and Tyski, S. (2015). Looking for New Preparations for Antibacterial Therapy. IV. New Antimicrobial Agents from the Aminoglycoside, Macrolide 
and Tetracycline Groups in Clinical Trials. Przegl Epidemiol. 69 (4), 723865-770770.

Katva, S., Das, S., Moti, H. S., Jyoti, A., and Kaushik, S. (2018). Antibacterial Synergy of Silver Nanoparticles with Gentamicin and Chloramphenicol against Enterococcus faecalis. Pharmacogn Mag. 13 (Suppl. 4), S828-s833. doi:10.4103/ pm.pm_120_17

Keogan, D. M., and Griffith, D. M. (2014). Current and Potential Applications of Bismuth-Based Drugs. Molecules 19 (9), 15258-15297. doi:10.3390/ molecules190915258

Kim, J. S., Heo, P., Yang, T. J., Lee, K. S., Jin, Y. S., Kim, S. K., et al. (2011). Bacterial Persisters Tolerate Antibiotics by Not Producing Hydroxyl Radicals. Biochem. Biophys. Res. Commun. 413 (1), 105-110. doi:10.1016/j.bbrc.2011.08.063

Kirkcaldy, R. D., Weinstock, H. S., Moore, P. C., Philip, S. S., Wiesenfeld, H. C., Papp, J. R., et al. (2014). The Efficacy and Safety of Gentamicin Plus Azithromycin and Gemifloxacin Plus Azithromycin as Treatment of Uncomplicated Gonorrhea. Clin. Infect. Dis. 59 (8), 1083-1091. doi:10.1093/ $\mathrm{cid} / \mathrm{ciu} 521$

Kohanski, M. A., Dwyer, D. J., Hayete, B., Lawrence, C. A., and Collins, J. J. (2007). A Common Mechanism of Cellular Death Induced by Bactericidal Antibiotics. Cell 130 (5), 797-810. doi:10.1016/j.cell.2007.06.049

Krahn, T., Gilmour, C., Tilak, J., Fraud, S., Kerr, N., Lau, C. H., et al. (2012). Determinants of Intrinsic Aminoglycoside Resistance in Pseudomonas aeruginosa. Antimicrob. Agents Chemother. 56 (11), 5591-5602. doi:10.1128/ aac.01446-12

Kros, C. J., and Steyger, P. S. (2019). Aminoglycoside- and Cisplatin-Induced Ototoxicity: Mechanisms and Otoprotective Strategies. Cold Spring Harb Perspect. Med. 9 (11). doi:10.1101/cshperspect.a033548

Kudo, F., and Eguchi, T. (2016). Aminoglycoside Antibiotics: New Insights into the Biosynthetic Machinery of Old Drugs. Chem. Rec. 16 (1), 4-18. doi:10.1002/tcr. 201500210

Le, J., McKee, B., Srisupha-Olarn, W., and Burgess, D. S. (2011). In Vitro activity of Carbapenems Alone and in Combination with Amikacin against KPCProducing Klebsiella pneumoniae. J. Clin. Med. Res. 3 (3), 106-110. doi:10. 4021/jocmr551w

Lebeaux, D., Ghigo, J. M., and Beloin, C. (2014). Biofilm-related Infections: Bridging the gap between Clinical Management and Fundamental Aspects of Recalcitrance toward Antibiotics. Microbiol. Mol. Biol. Rev. 78 (3), 510-543. doi:10.1128/mmbr.00013-14

Li, X. Z., Plésiat, P., and Nikaido, H. (2015). The challenge of Efflux-Mediated Antibiotic Resistance in Gram-Negative Bacteria. Clin. Microbiol. Rev. 28 (2), 337-418. doi:10.1128/cmr.00117-14

Lin, W. (2001). An Overview of the Development of Aminoglycoside. Strait Pharm. J. 13 (4), 5-9. doi:10.3969/j.issn.1006-3765.2001.04.002

Liu, S., Mai, B., Jia, M., Lin, D., Zhang, J., Liu, Q., et al. (2020). Synergistic Antimicrobial Effects of Photodynamic Antimicrobial Chemotherapy and Gentamicin on Staphylococcus aureus and Multidrug-Resistant Staphylococcus aureus. Photodiagnosis Photodyn Ther. 30, 101703. doi:10. 1016/j.pdpdt.2020.101703

Liu, S., Zeng, T. H., Hofmann, M., Burcombe, E., Wei, J., Jiang, R., et al. (2011). Antibacterial Activity of Graphite, Graphite Oxide, Graphene Oxide, and Reduced Graphene Oxide: Membrane and Oxidative Stress. ACS Nano 5 (9), 6971-6980. doi:10.1021/nn202451x

López Díaz, M. C., Ríos, E., Rodríguez-Avial, I., Simaluiza, R. J., Picazo, J. J., and Culebras, E. (2017). In-vitro Activity of Several Antimicrobial Agents against Methicillin-Resistant Staphylococcus aureus (MRSA) Isolates Expressing Aminoglycoside-Modifying Enzymes: Potency of Plazomicin Alone and in Combination with Other Agents. Int. J. Antimicrob. Agents 50 (2), 191-196. doi:10.1016/j.ijantimicag.2017.01.039

Ma, L., Wu, J., Wang, S., Yang, H., Liang, D., and Lu, Z. (2017). Synergistic Antibacterial Effect of Bi2S3 Nanospheres Combined with Ineffective Antibiotic Gentamicin against Methicillin-Resistant Staphylococcus aureus. J. Inorg. Biochem. 168, 38-45. doi:10.1016/j.jinorgbio.2016. 12.005

Macedo, I., da Silva, J. H., da Silva, P. T., Cruz, B. G., do Vale, J. P. C., Dos Santos, H. S., et al. (2019). Structural and Microbiological Characterization of 5-Hydroxy3,7,4'-Trimethoxyflavone: A Flavonoid Isolated from Vitex Gardneriana Schauer Leaves. Microb. Drug Resist. 25 (3), 434-438. doi:10.1089/mdr.2018. 0359
Manoraj, A., Thevanesam, V., Bandara, B. M. R., Ekanayake, A., and Liyanapathirana, V. (2019). Synergistic Activity between Triphala and Selected Antibiotics against Drug Resistant Clinical Isolates. $B M C$ Complement. Altern. Med. 19 (1), 199. doi:10.1186/s12906-019-2618-1

May, A. K. (2016). An Argument for the Use of Aminoglycosides in the Empiric Treatment of Ventilator-Associated Pneumonia. Surg. Infect. (Larchmt) 17 (3), 329-333. doi:10.1089/sur.2015.276

Mazur, P., Skiba-Kurek, I., Mrowiec, P., Karczewska, E., and Drożdż, R. (2020). Synergistic ROS-Associated Antimicrobial Activity of Silver Nanoparticles and Gentamicin against Staphylococcus Epidermidis. Int. J. Nanomedicine 15, 3551-3562. doi:10.2147/ijn.S246484

Meyer, R. (2009). Replication and Conjugative Mobilization of Broad Host-Range IncQ Plasmids. Plasmid 62 (2), 57-70. doi:10.1016/j.plasmid.2009.05.001

Miró, E., Grünbaum, F., Gómez, L., Rivera, A., Mirelis, B., Coll, P., et al. (2013). Characterization of Aminoglycoside-Modifying Enzymes in Enterobacteriaceae Clinical Strains and Characterization of the Plasmids Implicated in Their Diffusion. Microb. Drug Resist. 19 (2), 94-99. doi:10.1089/mdr.2012.0125

Mun, S. H., Joung, D. K., Kim, Y. S., Kang, O. H., Kim, S. B., Seo, Y. S., et al. (2013). Synergistic Antibacterial Effect of Curcumin against Methicillin-Resistant Staphylococcus aureus. Phytomedicine 20 (8-9), 714-718. doi:10.1016/j. phymed.2013.02.006

Nikaido, H., and Pagès, J. M. (2012). Broad-specificity Efflux Pumps and Their Role in Multidrug Resistance of Gram-Negative Bacteria. FEMS Microbiol. Rev. 36 (2), 340-363. doi:10.1111/j.1574-6976.2011.00290.x

Nosrati, M., Dey, D., Mehrani, A., Strassler, S. E., Zelinskaya, N., Hoffer, E. D., et al. (2019). Functionally Critical Residues in the Aminoglycoside ResistanceAssociated Methyltransferase RmtC Play Distinct Roles in 30S Substrate Recognition. J. Biol. Chem. 294 (46), 17642-17653. doi:10.1074/jbc.RA119. 011181

Obad, J., Šušković, J., and Kos, B. (2015). Antimicrobial Activity of Ibuprofen: New Perspectives on an "Old" Non-antibiotic Drug. Eur. J. Pharm. Sci. 71, 93-98. doi:10.1016/j.ejps.2015.02.011

Orsi, R. O., Fernandes, A., Bankova, V., and Sforcin, J. M. (2012). The Effects of Brazilian and Bulgarian Propolis In Vitro against Salmonella Typhi and Their Synergism with Antibiotics Acting on the Ribosome. Nat. Prod. Res. 26 (5), 430-437. doi:10.1080/14786419.2010.498776

Pan, X., Chen, S., Li, D., Rao, W., Zheng, Y., Yang, Z., et al. (2017). The Synergistic Antibacterial Mechanism of Gentamicin-Loaded CaCO 3 Nanoparticles. Front. Chem. 5, 130. doi:10.3389/fchem.2017.00130

Pang, Z., Raudonis, R., Glick, B. R., Lin, T. J., and Cheng, Z. (2019). Antibiotic Resistance in Pseudomonas aeruginosa: Mechanisms and Alternative Therapeutic Strategies. Biotechnol. Adv. 37 (1), 177-192. doi:10.1016/j. biotechadv.2018.11.013

Parveen, R., Shamsi, T. N., Singh, G., Athar, T., and Fatima, S. (2018). Phytochemical Analysis and In-Vitro Biochemical Characterization of Aqueous and Methanolic Extract of Triphala, a Conventional Herbal Remedy. Biotechnol. Rep. (Amst) 17, 126-136. doi:10.1016/j.btre.2018.02.003

Parvez, M. A. K., Saha, K., Rahman, J., Munmun, R. A., Rahman, M. A., Dey, S. K., et al. (2019). Antibacterial Activities of green tea Crude Extracts and Synergistic Effects of Epigallocatechingallate (EGCG) with Gentamicin against MDR Pathogens. Heliyon 5 (7), e02126. doi:10.1016/j.heliyon.2019.e02126

Pérez-Laguna, V., García-Luque, I., Ballesta, S., Pérez-Artiaga, L., Lampaya-Pérez, V., Samper, S., et al. (2018). Antimicrobial Photodynamic Activity of Rose Bengal, Alone or in Combination with Gentamicin, against Planktonic and Biofilm Staphylococcus aureus. Photodiagnosis Photodyn Ther. 21, 211-216. doi:10.1016/j.pdpdt.2017.11.012

Pérez-Laguna, V., Gilaberte, Y., Millán-Lou, M. I., Agut, M., Nonell, S., Rezusta, A., et al. (2019). A Combination of Photodynamic Therapy and Antimicrobial Compounds to Treat Skin and Mucosal Infections: a Systematic Review. Photochem. Photobiol. Sci. 18 (5), 1020-1029. doi:10.1039/c8pp00534f

Pérez-Laguna, V., Pérez-Artiaga, L., Lampaya-Pérez, V., García-Luque, I., Ballesta, S., Nonell, S., et al. (2017). Bactericidal Effect of Photodynamic Therapy, Alone or in Combination with Mupirocin or Linezolid, on Staphylococcus aureus. Front. Microbiol. 8, 1002. doi:10.3389/fmicb.2017.01002

Poole, K. (2011). Pseudomonas aeruginosa: Resistance to the max. Front. Microbiol. 2, 65. doi:10.3389/fmicb.2011.00065

Pusic, P., Sonnleitner, E., Krennmayr, B., Heitzinger, D. A., Wolfinger, M. T., Resch, A., et al. (2018). Harnessing Metabolic Regulation to Increase Hfq- 
Dependent Antibiotic Susceptibility in Pseudomonas aeruginosa. Front. Microbiol. 9, 2709. doi:10.3389/fmicb.2018.02709

Pusic, P., Tata, M., Wolfinger, M. T., Sonnleitner, E., Häussler, S., and Bläsi, U. (2016). Cross-regulation by CrcZ RNA Controls Anoxic Biofilm Formation in Pseudomonas aeruginosa. Sci. Rep. 6, 39621. doi:10.1038/srep39621

Ramirez, M. S., Nikolaidis, N., and Tolmasky, M. E. (2013). Rise and Dissemination of Aminoglycoside Resistance: the Aac(6')-Ib Paradigm. Front. Microbiol. 4, 121. doi:10.3389/fmicb.2013.00121

Ramírez, M. S., Quiroga, C., and Centrón, D. (2005). Novel Rearrangement of a Class 2 Integron in Two Non-epidemiologically Related Isolates of Acinetobacter Baumannii. Antimicrob. Agents Chemother. 49 (12), 5179-5181. doi:10.1128/aac.49.12.5179-5181.2005

Ramirez, M. S., and Tolmasky, M. E. (2017). Amikacin: Uses, Resistance, and Prospects for Inhibition. Molecules 22 (12). doi:10.3390/ molecules 22122267

Ramirez, M. S., and Tolmasky, M. E. (2010). Aminoglycoside Modifying Enzymes. Drug Resist. Updat 13 (6), 151-171. doi:10.1016/j.drup.2010.08.003

Regueira, M. S., Tintino, S. R., da Silva, A. R. P., Costa, M. D. S., Boligon, A. A., Matias, E. F. F., et al. (2017). Seasonal Variation of Brazilian Red Propolis: Antibacterial Activity, Synergistic Effect and Phytochemical Screening. Food Chem. Toxicol. 107 (Pt B), 572-580. doi:10.1016/j.fct.2017.03.052

Ren, H., Liu, Y., Zhou, J., Long, Y., Liu, C., Xia, B., et al. (2019). Combination of Azithromycin and Gentamicin for Efficient Treatment of Pseudomonas aeruginosa Infections. J. Infect. Dis. 220 (10), 1667-1678. doi:10.1093/infdis/ jiz341

Rhodes, A., Evans, L. E., Alhazzani, W., Levy, M. M., Antonelli, M., Ferrer, R., et al. (20172016). Surviving Sepsis Campaign: International Guidelines for Management of Sepsis and Septic Shock: 2016. Intensive Care Med. 43 (3), 304-377. doi:10.1007/s00134-017-4683-6

Rice, L. B. (2008). Federal Funding for the Study of Antimicrobial Resistance in Nosocomial Pathogens: No ESKAPE. J. Infect. Dis. 197 (8), 1079-1081. doi:10. $1086 / 533452$

Ristuccia, A. M., and Cunha, B. A. (1982). The Aminoglycosides. Med. Clin. North. Am. 66 (1), 303-312. doi:10.1016/s0025-7125(16)31462-6

Rosato, A., Piarulli, M., Corbo, F., Muraglia, M., Carone, A., Vitali, M. E., et al. (2010). In Vitro synergistic Antibacterial Action of Certain Combinations of Gentamicin and Essential Oils. Curr. Med. Chem. 17 (28), 3289-3295. doi:10. 2174/092986710792231996

Rosenberg, C. R., Fang, X., and Allison, K. R. (2020). Potentiating Aminoglycoside Antibiotics to Reduce Their Toxic Side Effects. PLoS One 15 (9), e0237948. doi:10.1371/journal.pone.0237948

Saravolatz, L. D., and Stein, G. E. (2020). Plazomicin: A New Aminoglycoside. Clin. Infect. Dis. 70 (4), 704-709. doi:10.1093/cid/ciz640

Schatz, A., Bugie, E., Waksman, S. A., Hanssen, A. D., Patel, R., and Osmon, D. R. (2005). Streptomycin, a Substance Exhibiting Antibiotic Activity against GramPositive and Gram-Negative Bacteria. 1944. Clin. Orthop. Relat. Res. 437, 3-6. doi:10.1097/01.blo.0000175887.98112.fe

Schmidt, S., Heymann, K., Melzig, M. F., Bereswill, S., and Heimesaat, M. M. (2016). Glycyrrhizic Acid Decreases Gentamicin-Resistance in VancomycinResistant Enterococci. Planta Med. 82 (18), 1540-1545. doi:10.1055/s-0042114781

Serio, A. W., Keepers, T., Andrews, L., and Krause, K. M. (2018). Aminoglycoside Revival: Review of a Historically Important Class of Antimicrobials Undergoing Rejuvenation. EcoSal Plus 8 (1). doi:10.1128/ ecosalplus.ESP-0002-2018

Serpersu, E. H., Ozen, C., and Wright, E. (2008). Studies of Enzymes that Cause Resistance to Aminoglycosides Antibiotics. Methods Mol. Med. 142, 261-271. doi:10.1007/978-1-59745-246-5_20

Shaul, P., Green, K. D., Rutenberg, R., Kramer, M., Berkov-Zrihen, Y., BreinerGoldstein, E., et al. (2011). Assessment of 6'- and 6"'-N-Acylation of Aminoglycosides as a Strategy to Overcome Bacterial Resistance. Org. Biomol. Chem. 9 (11), 4057-4063. doi:10.1039/c0ob01133a

Sick, A. C., Tschudin-Sutter, S., Turnbull, A. E., Weissman, S. J., and Tamma, P. D. (2014). Empiric Combination Therapy for Gram-Negative Bacteremia. Pediatrics 133 (5), el148-55. doi:10.1542/peds.2013-3363

Silva, A. C. A., Diodato, J. S., Castro, J. W., Matias, E. F. F., Silva, L. E., do Amaral, W., et al. (2019). Effect of the Essential Oils from Piper Sp. And Blue Led Lights in the Enhancement of the Antibiotic Activity of Drugs against Mdr Bacterial
Strains. J. Photochem. Photobiol. B 199, 111604. doi:10.1016/j.jphotobiol.2019. 111604

Singh, P., Kim, Y. J., Singh, H., Wang, C., Hwang, K. H., Farh, Mel-A., et al. (2015). Biosynthesis, Characterization, and Antimicrobial Applications of Silver Nanoparticles. Int. J. Nanomedicine 10, 2567-2577. doi:10.2147/ijn.S72313

Soler Bistué, A. J., Birshan, D., Tomaras, A. P., Dandekar, M., Tran, T., Newmark, J., et al. (2008). Klebsiella pneumoniae Multiresistance Plasmid pMET1: Similarity with the Yersinia pestis Plasmid pCRY and Integrative Conjugative Elements. PLoS One 3 (3), e1800. doi:10.1371/journal.pone. 0001800

Song, J. M., and Seong, B. L. (2007). Tea Catechins as a Potential Alternative Antiinfectious Agent. Expert Rev. Anti Infect. Ther. 5 (3), 497-506. doi:10.1586/ 14787210.5.3.497

Sonnleitner, E., Wulf, A., Campagne, S., Pei, X. Y., Wolfinger, M. T., Forlani, G., et al. (2018). Interplay between the Catabolite Repression Control Protein Crc, Hfq and RNA in Hfq-dependent Translational Regulation in Pseudomonas aeruginosa. Nucleic Acids Res. 46 (3), 1470-1485. doi:10.1093/nar/gkx1245

Sparo, M., Delpech, G., and García Allende, N. (2018). Impact on Public Health of the Spread of High-Level Resistance to Gentamicin and Vancomycin in Enterococci. Front. Microbiol. 9, 3073. doi:10.3389/fmicb.2018.03073

Srikumar, R., Parthasarathy, N. J., Shankar, E. M., Manikandan, S., Vijayakumar, R., Thangaraj, R., et al. (2007). Evaluation of the Growth Inhibitory Activities of Triphala against Common Bacterial Isolates from HIV Infected Patients. Phytother Res. 21 (5), 476-480. doi:10.1002/ptr.2105

Stead, D. A. (2000). Current Methodologies for the Analysis of Aminoglycosides. J. Chromatogr. B Biomed. Sci. Appl. 747 (1-2), 69-93. doi:10.1016/s03784347(00)00133-x

Stewart, P. S. (2002). Mechanisms of Antibiotic Resistance in Bacterial Biofilms. Int. J. Med. Microbiol. 292 (2), 107-113. doi:10.1078/1438-4221-00196

Sukhorukova, I. V., Sheveyko, A. N., Manakhov, A., Zhitnyak, I. Y., Gloushankova, N. A., Denisenko, E. A., et al. (2018). Synergistic and Long-Lasting Antibacterial Effect of Antibiotic-Loaded TiCaPCON-Ag Films against Pathogenic Bacteria and Fungi. Mater. Sci. Eng. C Mater. Biol. Appl. 90, 289-299. doi:10.1016/j. msec.2018.04.068

Syue, L. S., Chen, Y. H., Ko, W. C., and Hsueh, P. R. (2016). New Drugs for the Treatment of Complicated Intra-abdominal Infections in the Era of Increasing Antimicrobial Resistance. Int. J. Antimicrob. Agents 47 (4), 250-258. doi:10. 1016/j.ijantimicag.2015.12.021

Tambekar, D. H., and Dahikar, S. B. (2011). Antibacterial Activity of Some Indian Ayurvedic Preparations against Enteric Bacterial Pathogens. J. Adv. Pharm. Technol. Res. 2 (1), 24-29. doi:10.4103/2231-4040.79801

Tamma, P. D., Cosgrove, S. E., and Maragakis, L. L. (2012). Combination Therapy for Treatment of Infections with Gram-Negative Bacteria. Clin. Microbiol. Rev. 25 (3), 450-470. doi:10.1128/cmr.05041-11

Tavares, L. J., de Avila, E. D., Klein, M. I., Panariello, B. H. D., Spolidório, D. M. P., and Pavarina, A. C. (2018). Antimicrobial Photodynamic Therapy Alone or in Combination with Antibiotic Local Administration against Biofilms of Fusobacterium Nucleatum and Porphyromonas Gingivalis. J. Photochem. Photobiol. B 188, 135-145. doi:10.1016/j.jphotobiol.2018.09.010

Tolmasky, M. E. (2000). Bacterial Resistance to Aminoglycosides and BetaLactams: the Tn1331 Transposon Paradigm. Front. Biosci. 5, D20-D29. doi:10.2741/tolmasky

Trombetta, D., Castelli, F., Sarpietro, M. G., Venuti, V., Cristani, M., Daniele, C., et al. (2005). Mechanisms of Antibacterial Action of Three Monoterpenes. Antimicrob. Agents Chemother. 49 (6), 2474-2478. doi:10.1128/aac.49.6.24742478.2005

Tsai, A., Uemura, S., Johansson, M., Puglisi, E. V., Marshall, R. A., Aitken, C. E., et al. (2013). The Impact of Aminoglycosides on the Dynamics of Translation Elongation. Cell Rep 3 (2), 497-508. doi:10.1016/j.celrep.2013.01.027

Ullah, S., Ahmad, A., Subhan, F., Jan, A., Raza, M., Khan, A. U., et al. (2018). Tobramycin Mediated Silver Nanospheres/graphene Oxide Composite for Synergistic Therapy of Bacterial Infection. J. Photochem. Photobiol. B 183, 342-348. doi:10.1016/j.jphotobiol.2018.05.009

Vakulenko, S. B., and Mobashery, S. (2003). Versatility of Aminoglycosides and Prospects for Their Future. Clin. Microbiol. Rev. 16 (3), 430-450. doi:10.1128/ cmr.16.3.430-450.2003

Vilchèze, C., Hartman, T., Weinrick, B., Jain, P., Weisbrod, T. R., Leung, L. W., et al. (2017). Enhanced Respiration Prevents Drug Tolerance and Drug 
Resistance in Mycobacterium tuberculosis. Proc. Natl. Acad. Sci. U S A. 114 (17), 4495-4500. doi:10.1073/pnas.1704376114

Vitko, N. P., Spahich, N. A., and Richardson, A. R. (2015). Glycolytic Dependency of High-Level Nitric Oxide Resistance and Virulence in Staphylococcus aureus. mBio 6 (2). doi:10.1128/mBio.00045-15

Vrabec, G., Stevenson, W., Elguizaoui, S., Kirsch, M., and Pinkowski, J. (2016). What Is the Intraarticular Concentration of Tobramycin Using Low-Dose Tobramycin Bone Cement in TKA: An In Vivo Analysis? Clin. Orthop. Relat. Res. 474 (11), 2441-2447. doi:10.1007/s11999-016-5006-x

Wachino, J. I., Doi, Y., and Arakawa, Y. (2020). Aminoglycoside Resistance: Updates with a Focus on Acquired 16S Ribosomal RNA Methyltransferases. Infect. Dis. Clin. North. Am. 34 (4), 887-902. doi:10.1016/j.idc.2020.06.002

Wainwright, M., O'Kane, C., and Rawthore, S. (2016). Phenothiazinium Photosensitisers XI. Improved Toluidine Blue Photoantimicrobials. J. Photochem. Photobiol. B 160, 68-71. doi:10.1016/j.jphotobiol.2016.03.035

Walters, M. C., 3rd, Roe, F., Bugnicourt, A., Franklin, M. J., and Stewart, P. S. (2003). Contributions of Antibiotic Penetration, Oxygen Limitation, and Low Metabolic Activity to Tolerance of Pseudomonas aeruginosa Biofilms to Ciprofloxacin and Tobramycin. Antimicrob. Agents Chemother. 47 (1), 317-323. doi:10.1128/aac.47.1.317-323.2003

Wang, L., Pulk, A., Wasserman, M. R., Feldman, M. B., Altman, R. B., Cate, J. H., et al. (2012). Allosteric Control of the Ribosome by Small-Molecule Antibiotics. Nat. Struct. Mol. Biol. 19 (9), 957-963. doi:10.1038/nsmb.2360

Wang, Z., Zhang, L., Wang, J., Wei, D., Shi, B., and Shan, A. (2014). Synergistic Interaction of PMAP-36 and PRW4 with Aminoglycoside Antibiotics and Their Antibacterial Mechanism. World J. Microbiol. Biotechnol. 30 (12), 3121-3128. doi:10.1007/s11274-014-1739-4

Wasserman, M. R., Pulk, A., Zhou, Z., Altman, R. B., Zinder, J. C., Green, K. D., et al. (2015). Chemically Related 4,5-linked Aminoglycoside Antibiotics Drive Subunit Rotation in Opposite Directions. Nat. Commun. 6, 7896. doi:10.1038/ ncomms 8896

Wilson, D. N. (2014). Ribosome-targeting Antibiotics and Mechanisms of Bacterial Resistance. Nat. Rev. Microbiol. 12 (1), 35-48. doi:10.1038/ nrmicro3155

Wilton, M., Charron-Mazenod, L., Moore, R., and Lewenza, S. (2016). Extracellular DNA Acidifies Biofilms and Induces Aminoglycoside Resistance in Pseudomonas aeruginosa. Antimicrob. Agents Chemother. 60 (1), 544-553. doi:10.1128/aac.01650-15

Xia, Y., Wang, D., Pan, X., Xia, B., Weng, Y., Long, Y., et al. (2020). TpiA Is a Key Metabolic Enzyme that Affects Virulence and Resistance to Aminoglycoside Antibiotics through CrcZ in Pseudomonas aeruginosa. mBio 11 (1). doi:10. 1128/mBio.02079-19

Xiao, Z. Y., Shiu, W. K. P., Zeng, Y. H., Mu, Q., and Gibbons, S. (2008). A Naturally Occurring Inhibitory Agent fromHypericum Sampsonii. With Activity against
Multidrug-ResistantStaphylococcus Aureus. Pharm. Biol. 46 (4), 250-253. doi:10.1080/13880200701739405

Xiong, L., Teng, J. L., Botelho, M. G., Lo, R. C., Lau, S. K., and Woo, P. C. (2016). Arginine Metabolism in Bacterial Pathogenesis and Cancer Therapy. Int. J. Mol. Sci. 17 (3), 363. doi:10.3390/ijms17030363

Yang, K., Zhang, S., Zhang, G., Sun, X., Lee, S. T., and Liu, Z. (2010). Graphene in Mice: Ultrahigh In Vivo Tumor Uptake and Efficient Photothermal Therapy. Nano Lett. 10 (9), 3318-3323. doi:10.1021/nl100996u

Yarlagadda, V., and Wright, G. D. (2019). Membrane-Active Rhamnolipids Overcome Aminoglycoside Resistance. Cell Chem Biol 26 (10), 1333-1334. doi:10.1016/j.chembiol.2019.09.015

Yeung, A. T., Gellatly, S. L., and Hancock, R. E. (2011). Multifunctional Cationic Host Defence Peptides and Their Clinical Applications. Cell Mol Life Sci 68 (13), 2161-2176. doi:10.1007/s00018-011-0710-x

Yin, Z., Wang, Y., Whittell, L. R., Jergic, S., Liu, M., Harry, E., et al. (2014). DNA Replication Is the Target for the Antibacterial Effects of Nonsteroidal Antiinflammatory Drugs. Chem. Biol. 21 (4), 481-487. doi:10.1016/j.chembiol.2014. 02.009

Zhang, L., Xia, J., Zhao, Q., Liu, L., and Zhang, Z. (2010). Functional Graphene Oxide as a Nanocarrier for Controlled Loading and Targeted Delivery of Mixed Anticancer Drugs. Small 6 (4), 537-544. doi:10.1002/smll.200901680

Zhao, Z. P., Liu, T. T., Zhang, L., Luo, M., Nie, X., Li, Z. X., et al. (2014). High-grade Mutant OmpF Induces Decreased Bacterial Survival Rate. Acta Biochim. Pol. 61 (2), 369-373. doi:10.18388/abp.2014_1908

Zhou, M., Zhai, Y., and Dong, S. (2009). Electrochemical Sensing and Biosensing Platform Based on Chemically Reduced Graphene Oxide. Anal. Chem. 81 (14), 5603-5613. doi:10.1021/ac900136z

Conflict of Interest: The authors declare that the research was conducted in the absence of any commercial or financial relationships that could be construed as a potential conflict of interest.

Publisher's Note: All claims expressed in this article are solely those of the authors and do not necessarily represent those of their affiliated organizations, or those of the publisher, the editors and the reviewers. Any product that may be evaluated in this article, or claim that may be made by its manufacturer, is not guaranteed or endorsed by the publisher.

Copyright $\odot 2022$ Wang, Luo, Deng, Huang and Zhou. This is an open-access article distributed under the terms of the Creative Commons Attribution License (CC BY). The use, distribution or reproduction in other forums is permitted, provided the original author(s) and the copyright owner(s) are credited and that the original publication in this journal is cited, in accordance with accepted academic practice. No use, distribution or reproduction is permitted which does not comply with these terms. 